\title{
Transatlantica
}

Revue d'études américaines. American Studies Journal

\section{Le Grain et la bulle : photographies du catalogue New York USA (2002) de Dolores Marat}

\section{Muriel Adrien}

\section{(2) OpenEdition}

1 Journals

\section{Édition électronique}

URL : https://journals.openedition.org/transatlantica/6749

DOI : $10.4000 /$ transatlantica. 6749

ISSN : 1765-2766

Éditeur

Association française d'Etudes Américaines (AFEA)

\section{Édition imprimée}

Date de publication : 31 décembre 2013

\section{Référence électronique}

Muriel Adrien, « Le Grain et la bulle : photographies du catalogue New York USA (2002) de Dolores Marat », Transatlantica [En ligne], 2 | 2013, mis en ligne le 25 septembre 2014, consulté le 01 février 2023. URL : http://journals.openedition.org/transatlantica/6749; DOI : https://doi.org/10.4000/ transatlantica.6749

Ce document a été généré automatiquement le 1 février 2023.

\section{(c) (i) $\odot$}

Creative Commons - Attribution - Pas d'Utilisation Commerciale - Pas de Modification 4.0 International - CC BY-NC-ND 4.0

https://creativecommons.org/licenses/by-nc-nd/4.0/ 


\title{
Le Grain et la bulle : photographies du catalogue New York USA (2002) de Dolores Marat
}

\author{
Muriel Adrien
}

J'ai rencontré Dolores Marat le 24 août 2013 chez elle en Avignon. Sa parole a été très libre et généreuse. N'étant pas autorisée à rendre publics les événements les plus intimes qu'elle m'a relatés, j'ai choisi ici de retranscrire une version expurgée de cet entretien. En revanche, je n'ai pas modifié ses réponses, comme en témoignent les nombreuses traces d'oralité. "

Je la remercie chaleureusement pour la générosité qu'elle a eue à m'accorder un entretien, qui plus est chez elle, et à me donner l'autorisation de reproduire les photographies. 


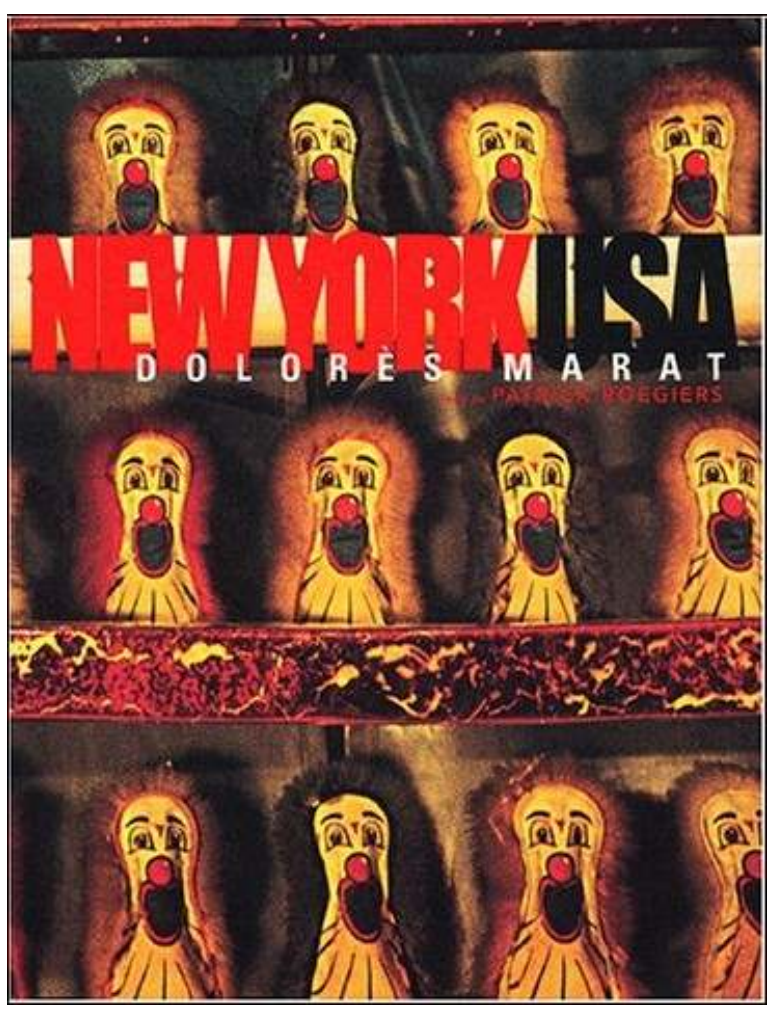

«New York, Sans titre [n.d] », page de couverture

1 Après un séjour à New York en 1994 pour une commande de magazine, Dolores Marat s'était promise d'y retourner. Sept années durant, elle effectua trois à quatre courts séjours par an pour arpenter la ville fébrilement avec son appareil. Dolores Marat rassembla les prises de vue ainsi glanées lors de ses déambulations dans un épais catalogue intitulé New York USA, publié aux Editions Marval en 2002. Quand on lui demande de qualifier son New York, Dolores Marat répond de manière sibylline: "Maratéen " ${ }^{1}$. Nous essaierons de voir ce que recouvre ce qualificatif, de repérer les constantes et caractéristiques de son univers visuel et ce qu'elles disent de la démarche et de l'esprit de l'artiste. En effet, de l'air de tristesse légère qui flotte autour de cet univers gris et terni, émane une grâce discrète mais lancinante. Loin de la foule, de la cacophonie et de l'ivresse du mouvement perpétuel de cette mégalopole, Dolores Marat capte un silence étouffé, un arrêt diffus et velouté, des solitudes mornes, labiles et incertaines, entre chien et loup. Le propos est de voir comment opèrent l'attrait et le charme de ces photos qui révèlent doucement une grande sensibilité.

2 Quand on lui demande les raisons qui président au choix de ses prises de vues, Dolores Marat dit qu'elle n'appuie sur le bouton que lorsqu'elle sent, l'espace d'un instant, une réminiscence furtive de son histoire personnelle. À New York, il était d'autant plus aisé de capter des impressions de souvenirs que la ville était étrangère à son passé intime, et qu'elle lui fournissait donc un alibi commode qui ne l'engageait pas.

3 Ce passé intime, elle le trouve dans des instants arrachés à l'anodin, au très ordinaire de la ville, à ce que l'on ne remarque pas, et elle leur accorde une attention tout en suspension et gravité. Dans ce mélange d'apesanteur et de pesanteur, elle rappelle avec une grande sincérité la distance essentielle qui sépare tout être d'un autre, et par là, l'état d'abandon irréductible consubstantiel à toute vie. 


\section{Des personnages « dans leurs bulles »}

4 La grande majorité des photographies de Dolores Marat montre des figures solitaires, perdues dans leurs pensées, parfois voûtées, rendues à leur destin.

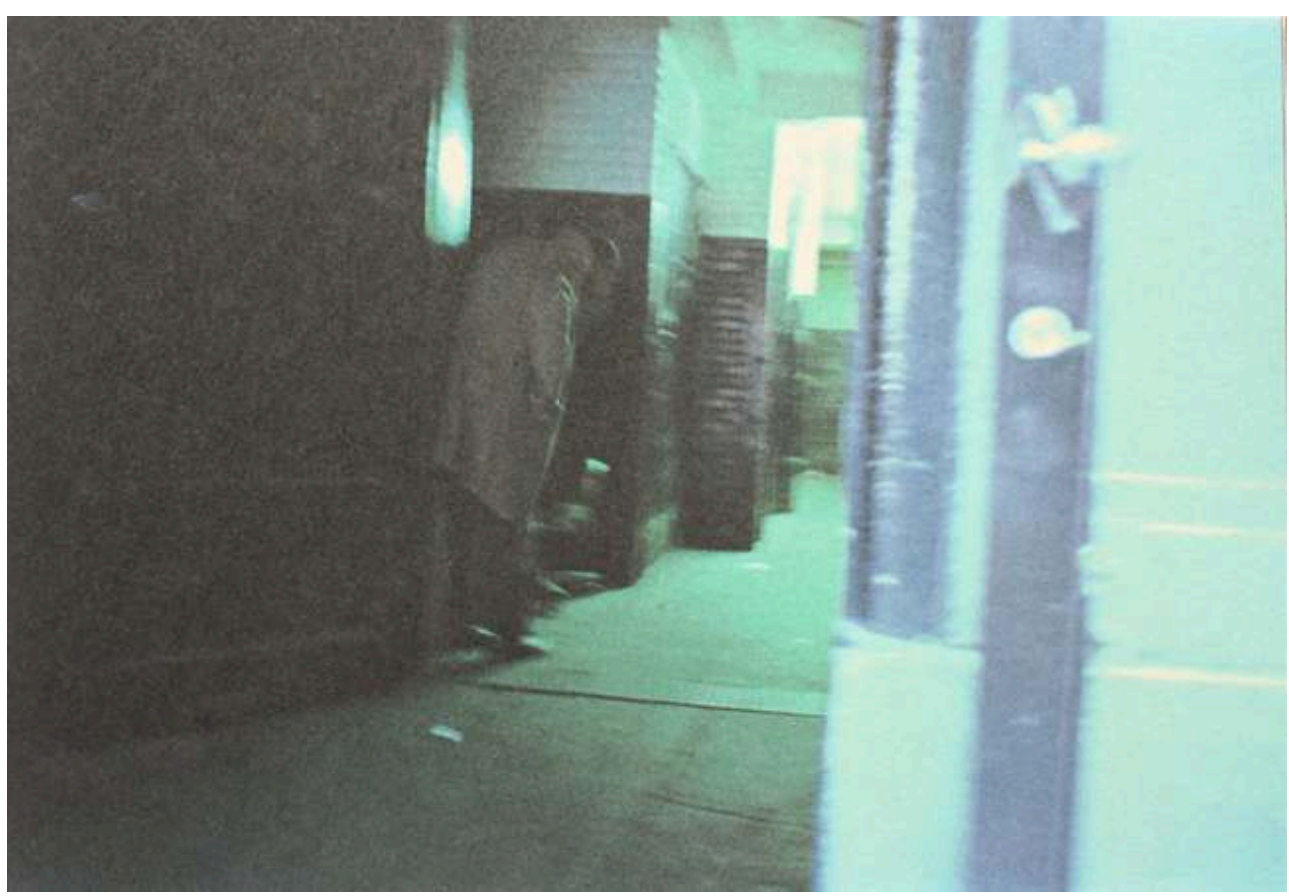

« New York, Sans titre [n.d] », p. 23

5 Leur isolement s'accompagne d'une impression de vulnérabilité, qu'elles compensent en se retirant dans «leur bulle ». Ce sont des personnages au repos, qui baissent la garde, comme la femme qui s'allonge à moitié sur son lit $(121)^{2}$. Ces personnages songeurs $(144,89)$ sont présentés souvent de dos $(65)$, regardant par une fenêtre dont on ne voit pas l'extérieur (81). 


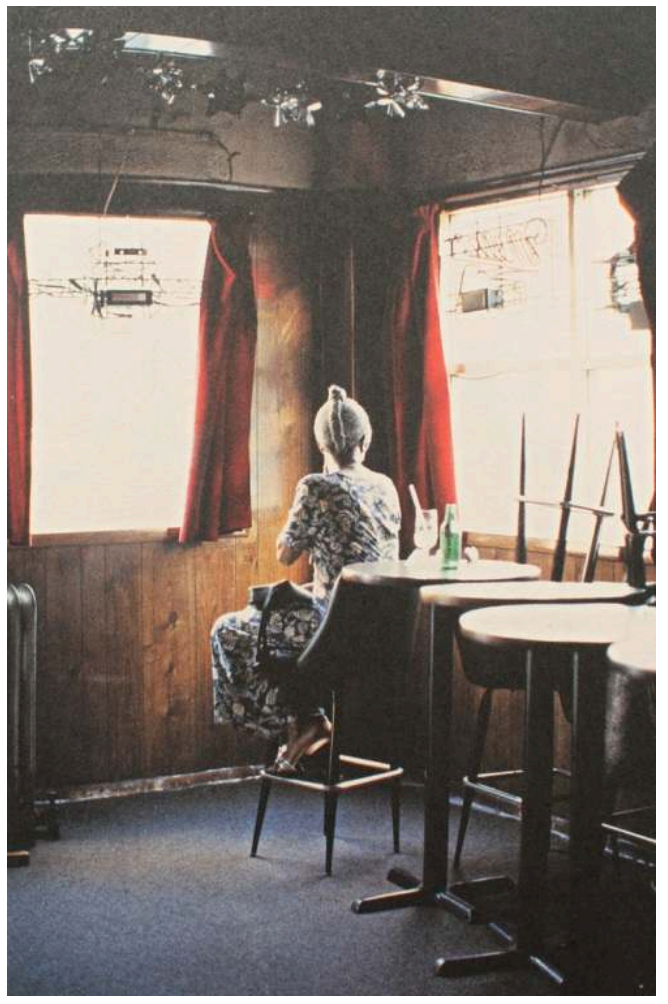

«New York, Sans titre [n.d] », p. 65

6 Ils semblent en attente comme des figures hopperiennes (49), dans un état de suspension ou de vacance irréelle ${ }^{3}$. Ces silhouettes souvent peu identifiables sont saisies dans un immobilisme feutré, en stase dans une parenthèse temporelle.

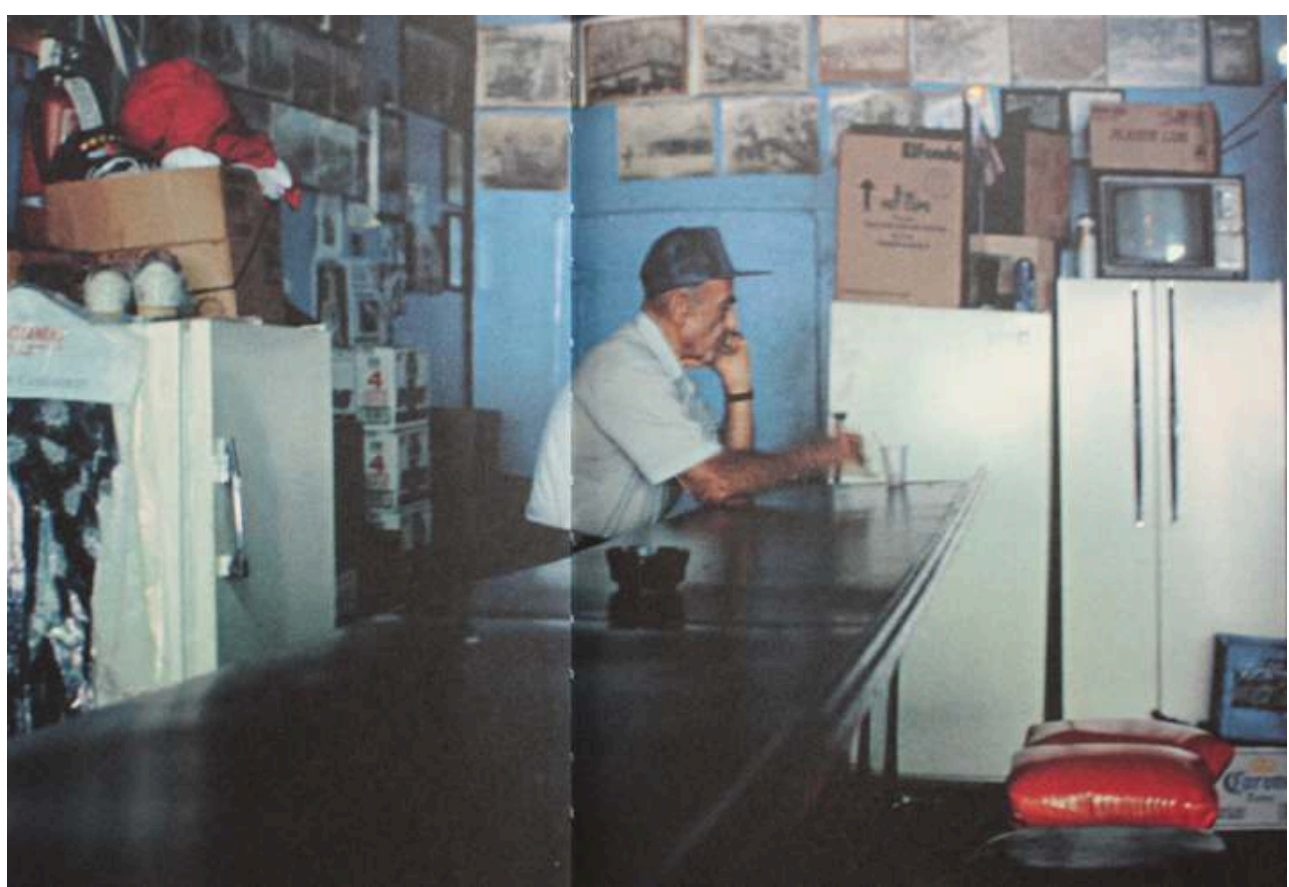

« New York, Sans titre [n.d] », p. 206-207 
7 Par exemple, un personnage isolé est aperçu derrière des plantes dans un petit restaurant piteux, éclairé par la tonalité verdâtre des néons, comme dans un aquarium (66-67).

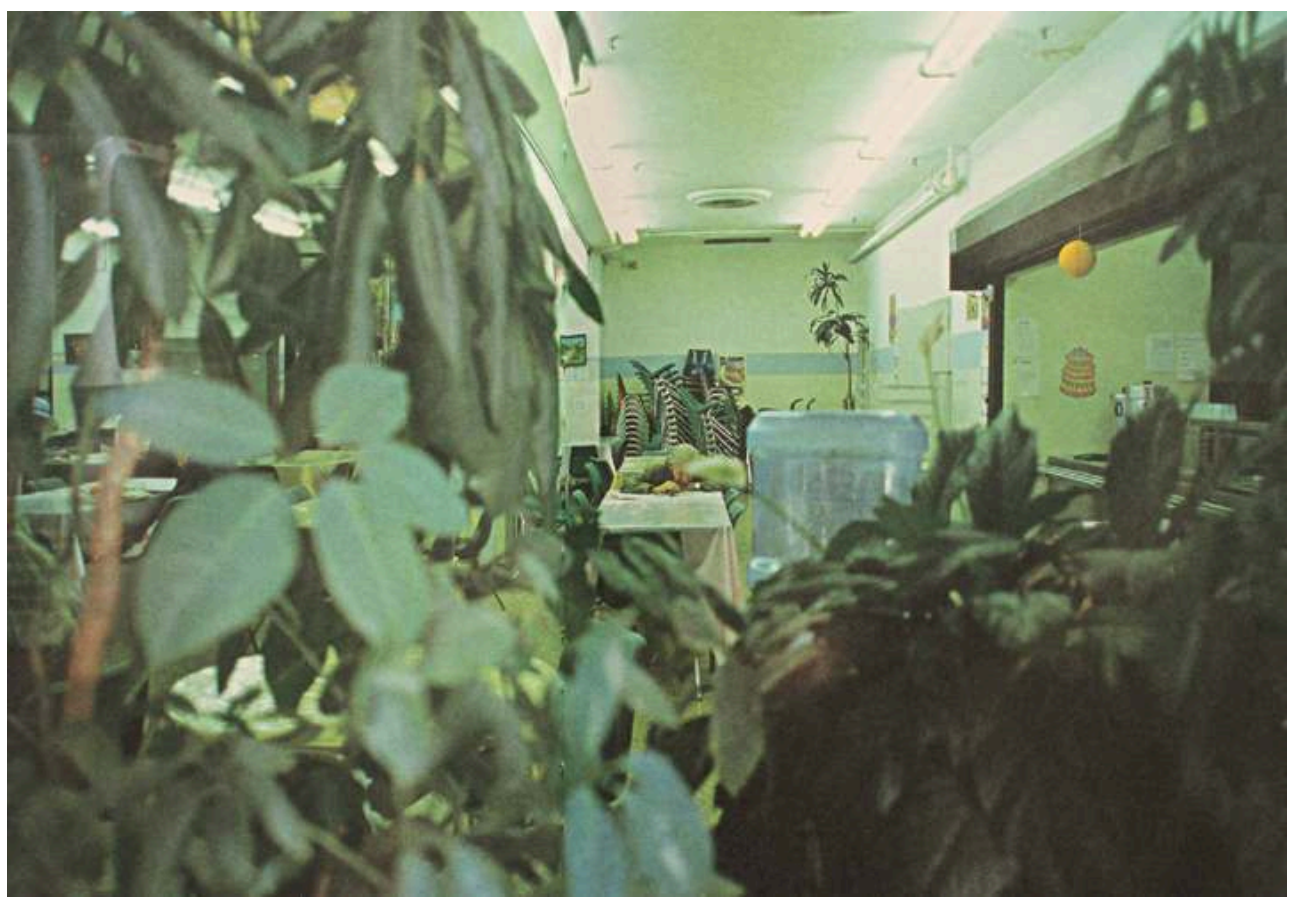

« New York, Sans titre [n.d] », p. 66-67

8 Les très rares scènes de rencontre ne sont pas aisées. En témoignent ces deux personnages comprimés entre deux portes (108).

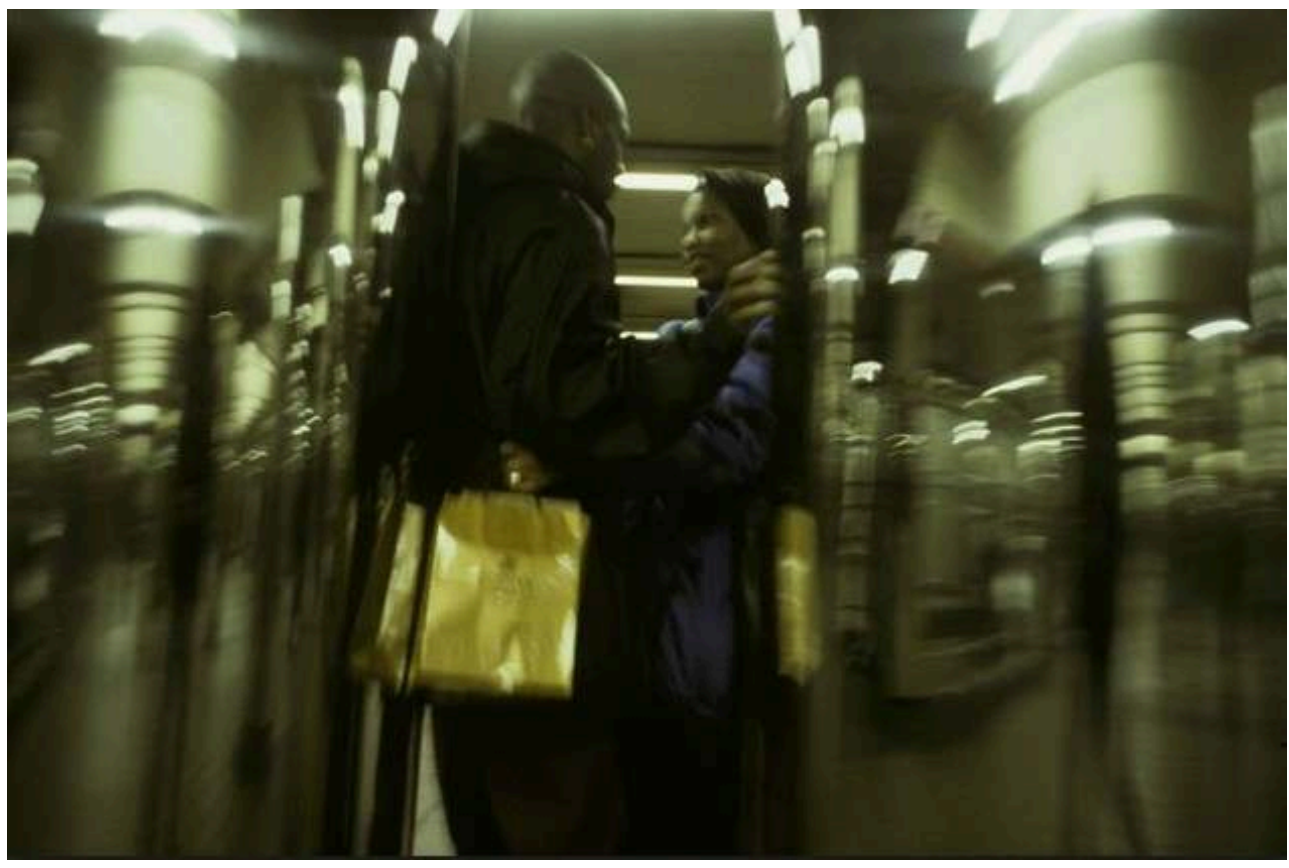

« New York, Sans titre [n.d] », p. 108

9 Sans doute ces scènes rappellent-elles à Dolores Marat sa propre enfance, qu'elle décrit comme une période de "quasi autisme $»^{4}$, notamment ses souvenirs de cours de 
récréation où elle se repliait sur elle-même, en réaction aux circonstances de son histoire personnelle.

\section{Bulles : fenêtres, voitures ou métro}

10 Les fenêtres vers lesquelles les personnages portent leur regard ne sont en rien des échappatoires $(89,112)$. Loin d'être ouvertes sur le monde, elles sont en verre dépoli, carrément opaques ou montrent tout au plus une très faible profondeur de champ, par exemple le mur du métro devant lequel défile le wagon (89).

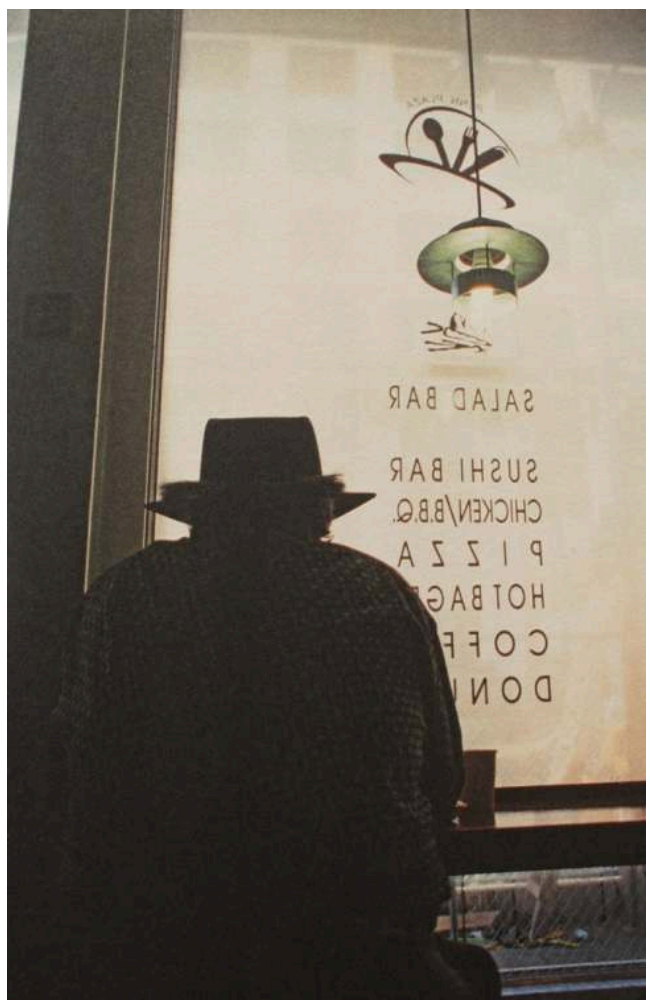

« New York, Sans titre [n.d] », p. 81

11 Le point de vue du photographe peut changer, mais la «bulle » demeure: ces personnages se trouvent parfois non plus devant les vitres ou vitrines, mais derrière (162-3, 173, 174-5, 177). Ces vitres, qui agissent comme des paravents ou des filtres, séparent l'espace du photographié et l'espace de la photographe, et protège son regard. Et matérialisent et redoublent le " prisme " photographique. 


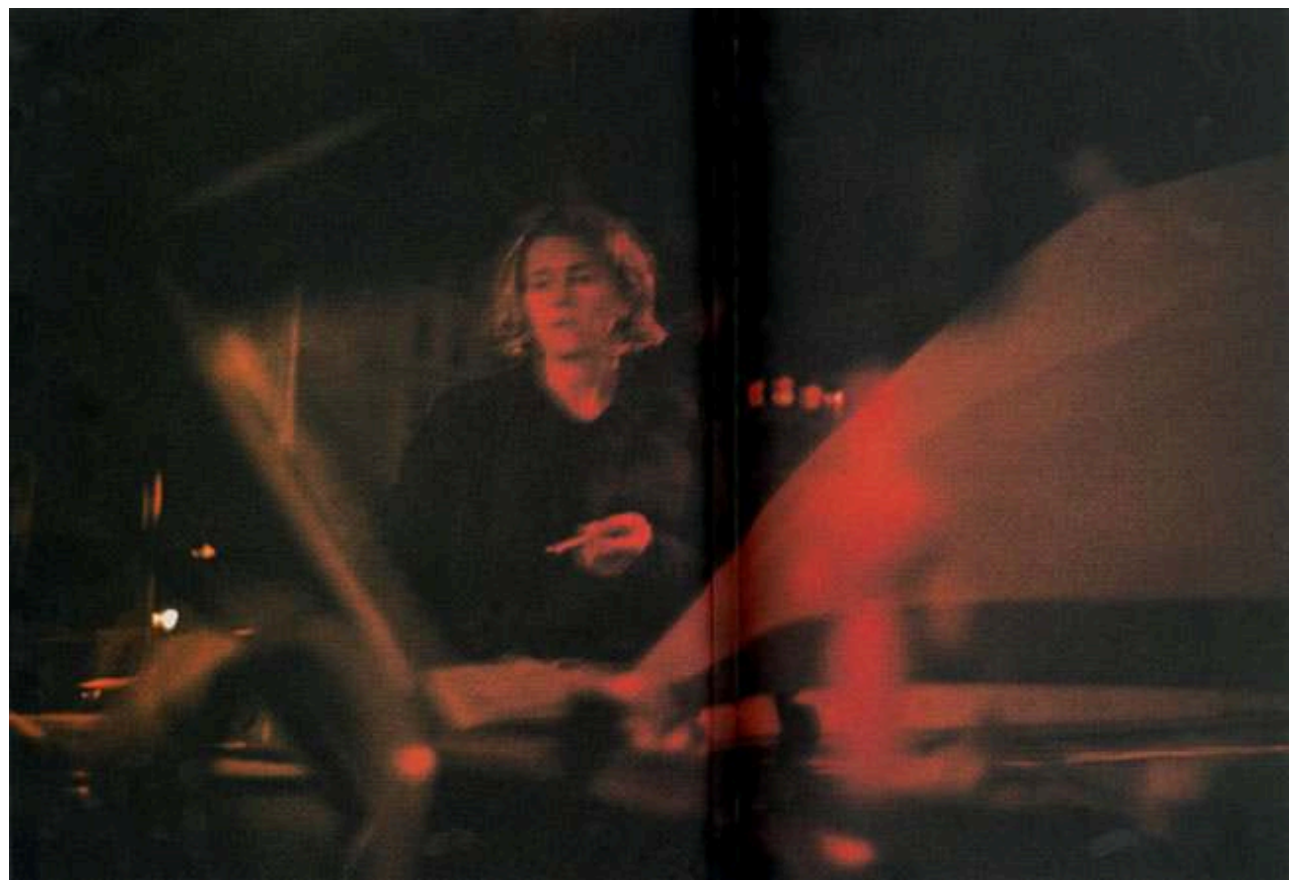

« New York, Sans titre [n.d] », p. 54-55

12 Les lieux représentés sont souvent des bars ou des cafés vides légèrement miteux (52, 206-7). Parfois les personnages sont aperçus derrière des vitrines dans lesquelles se reflètent aussi des voitures (112). Il n'est pas anodin que les voitures figurent parmi des leitmotivs, comme autant de «bulles » concrètes. Ces voitures sont en effet souvent à l'arrêt, rangées, garées devant un mur très graphique $(74,114-5,130-1,152,177)$, parfois vues d'une autre voiture (177).

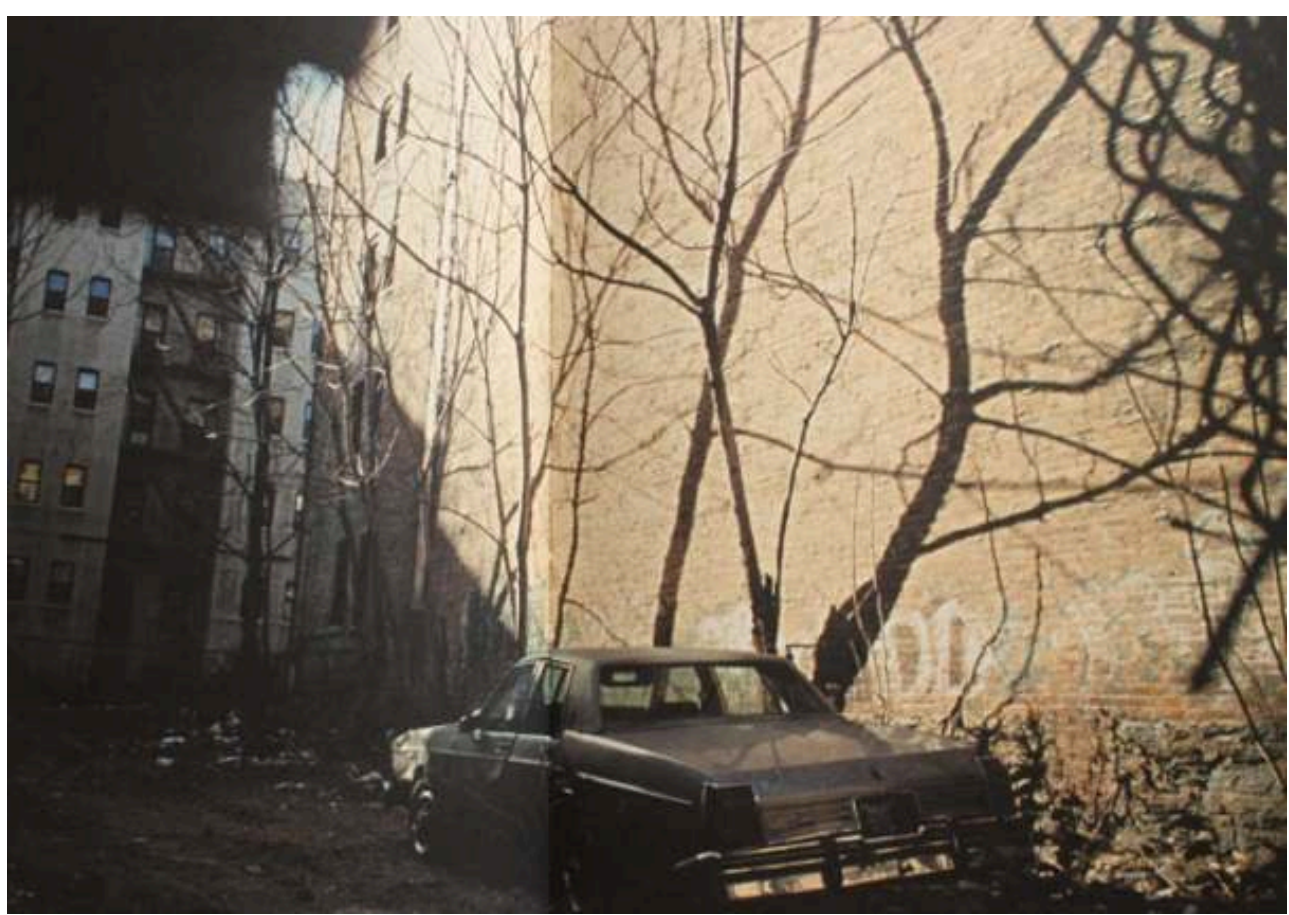

« New York, Sans titre [n.d] », p. 130-1 
13 Elles sont surannées ou vintage, dégradées ou rutilantes, comme cette limousine blanche devant un mur anthracite (172).

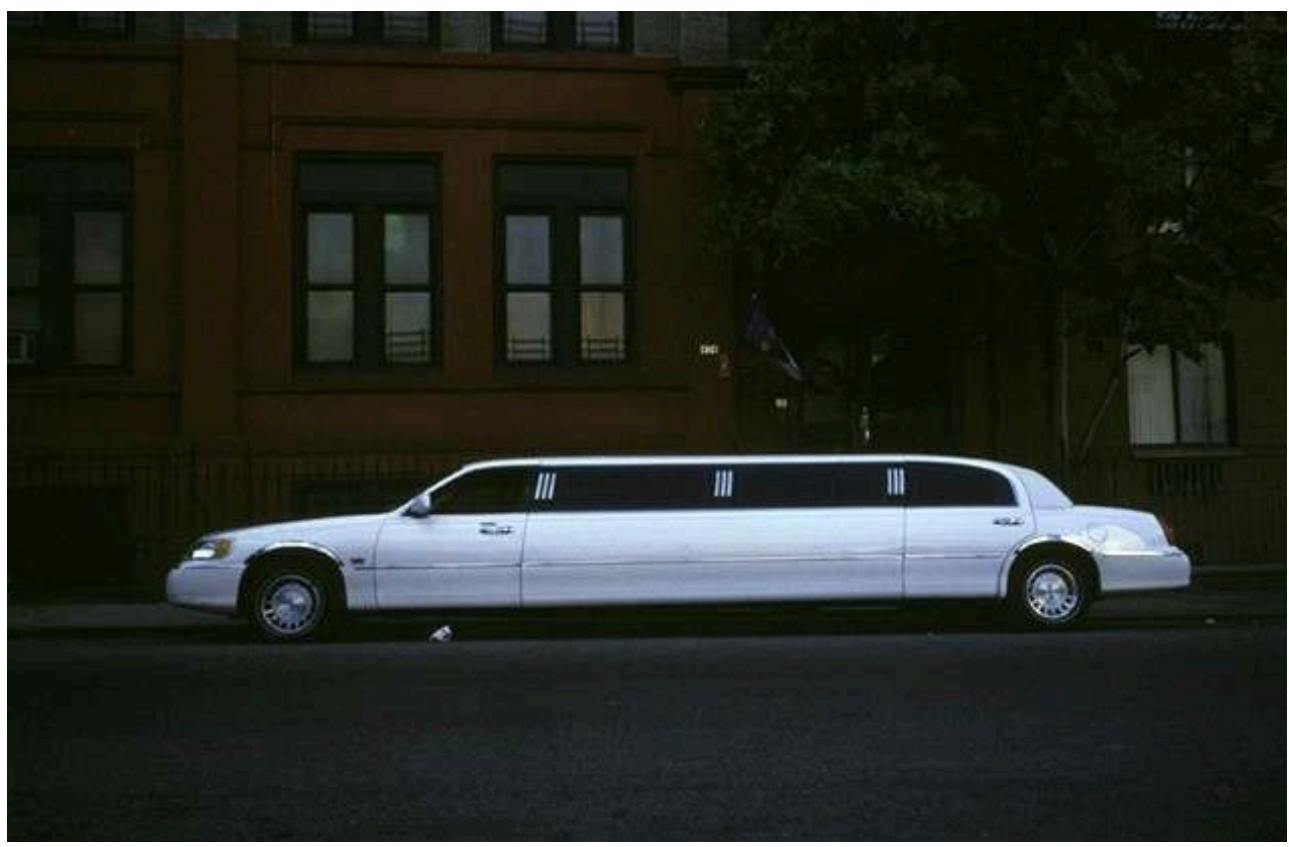

« New York, Sans titre [n.d] », p. 172

14 Autres lieux de prédilection, autres «bulles » : les parkings $(106-7,142)$, le métro (126, 198-9), lieux de transit et de transition, entre-deux où l'on ne s'établit pas, où l'on ne demeure pas.

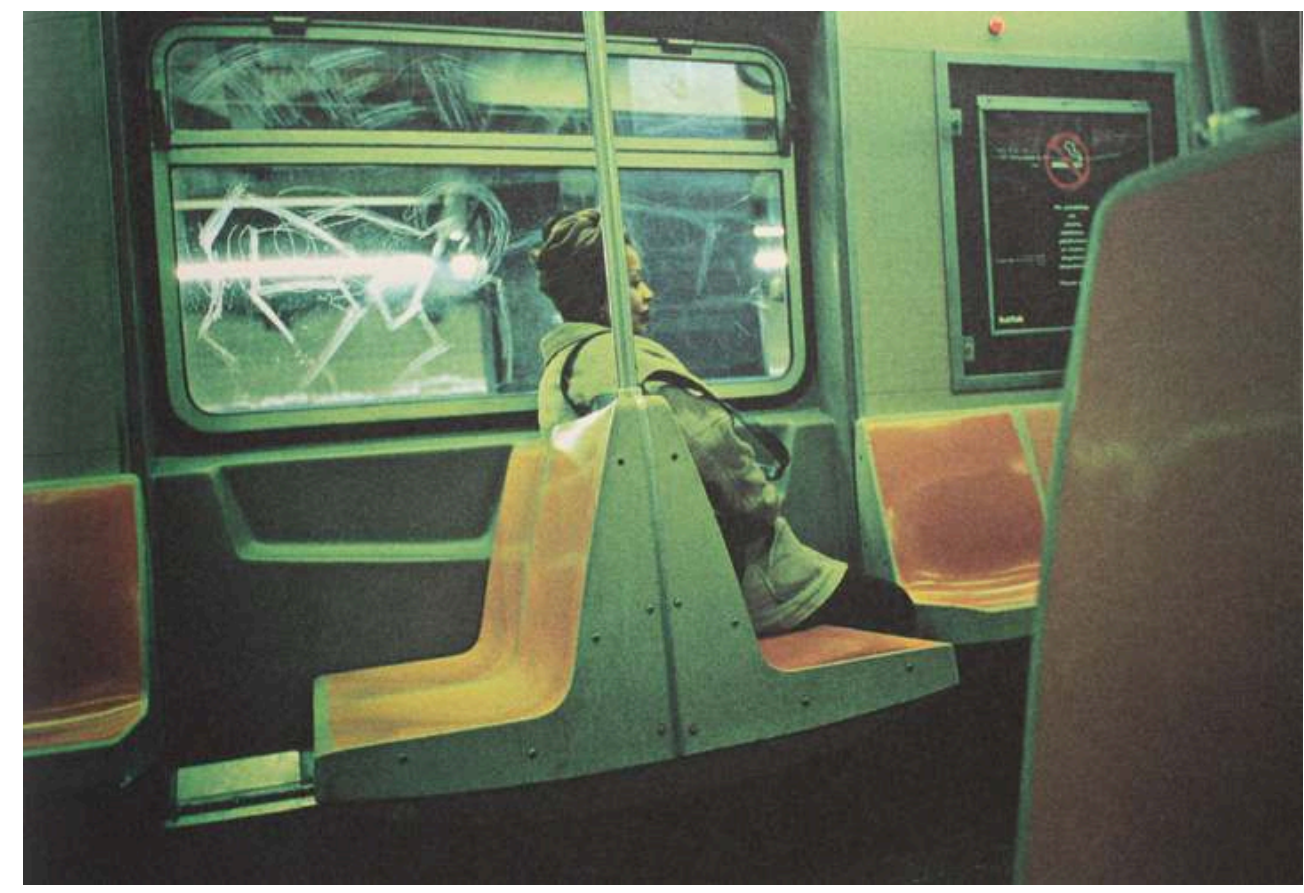

« New York, Sans titre [n.d] », p. 89

On se souvient que Dolores Marat avait eu un projet sur le métro parisien, finalement concrétisé en livre d'auteur cousu main par ses soins, combinant le texte et l'image ${ }^{5}$. 


\section{Terrains vagues}

16 Si les personnages sont livrés à eux-mêmes, les lieux extérieurs représentés le sont tout autant. Ce sont des lieux sans identité, des arrière-cours ou des terrains vagues représentés de manière tout aussi vague. Désertés, ils ont pourtant des relents de claustrophobie. Ils sont souvent jonchés de débris, décombres et déchets, à l'état d'abandon $(106-7,145)$.

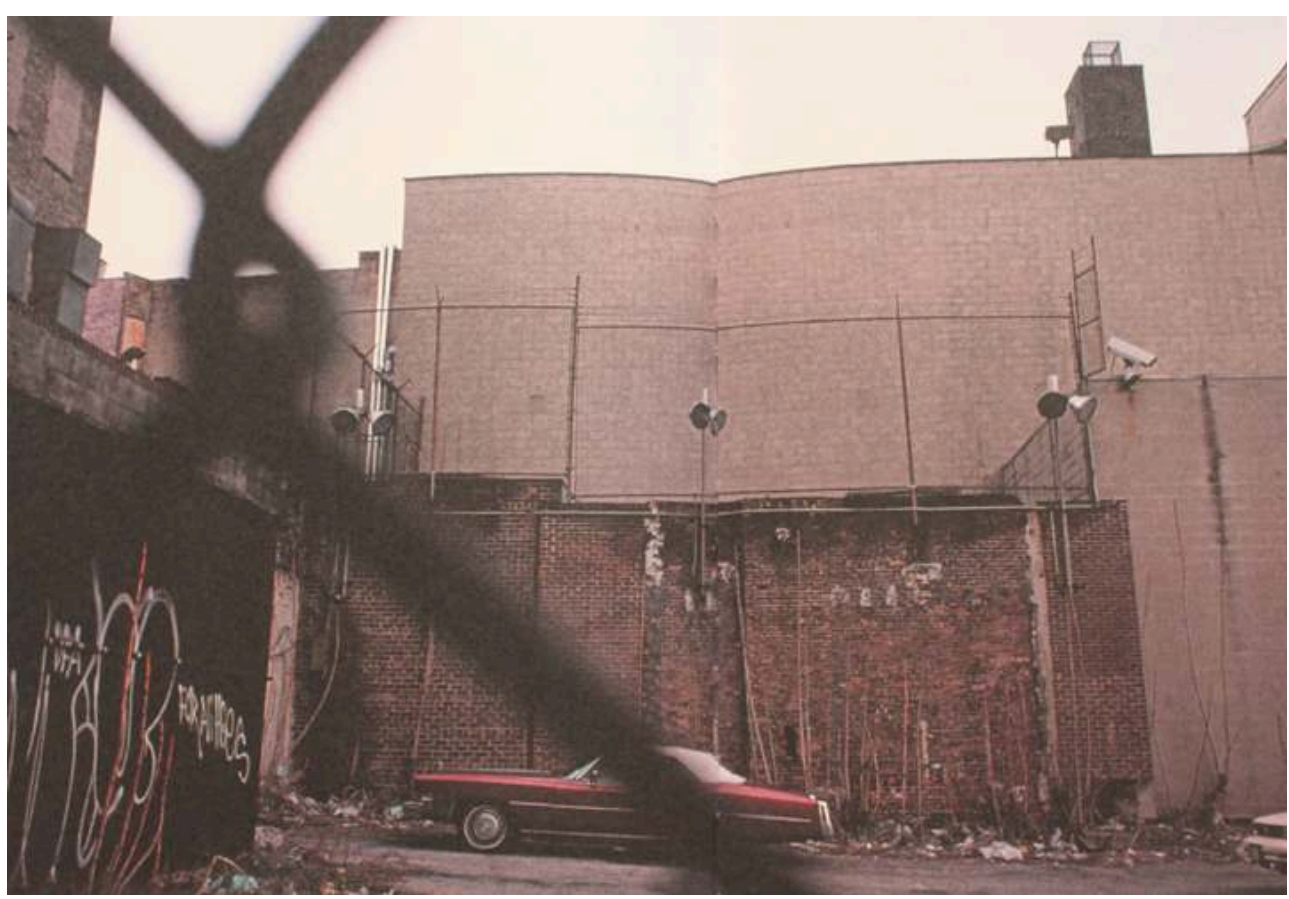

« New York, Sans titre [n.d] », p. 84-5

Devant des façades délabrées, des détritus ont été jetés, sans que l'endroit soit vraiment une décharge. Si les lieux servent de dépotoirs, ils n'ont même pas la noblesse de l'être officiellement. Ils sont vidés de toute fonction, en friche, en attente, comme dans un état de limbes incertain. Il n'empêche que Dolores Marat leur donne l'honneur de la double page. Dans un exemple, une impasse est barrée au premier plan par des sacs poubelle, mais la vue en plongée lui donne une profondeur paradoxale (53). 


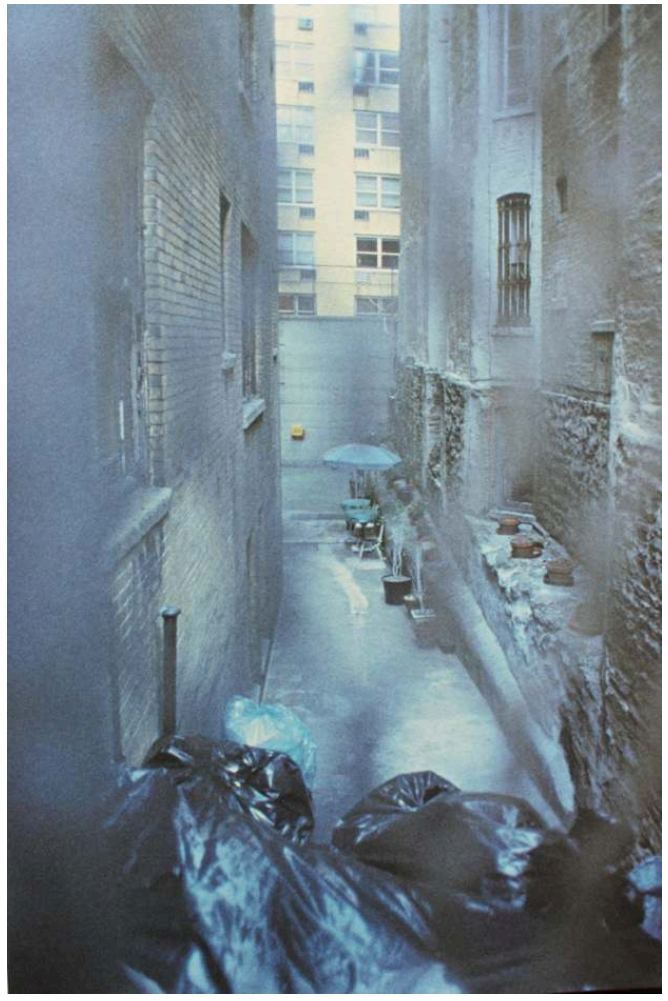

« New York, Sans titre [n.d] », p. 53

18 L'on trouve aussi, dans ses photos, un penchant pour la signalétique indiquant une interdiction de pénétrer ou encore une indication de sortie. Les pancartes vont de « Do not enter » (118), « No exit » (120, 160, 166-7), « Exit » (dont un avec un envol d'oiseaux, en un clin d'œil humoristique 138-9), «Keep out » (accompagné de "Danger - high voltage » 132-3), «Caution » (137), à " No thru traffic », avec un tunnel pour seule issue (140-1), indiquant pour seule voie de sortie, les dehors de la photo.

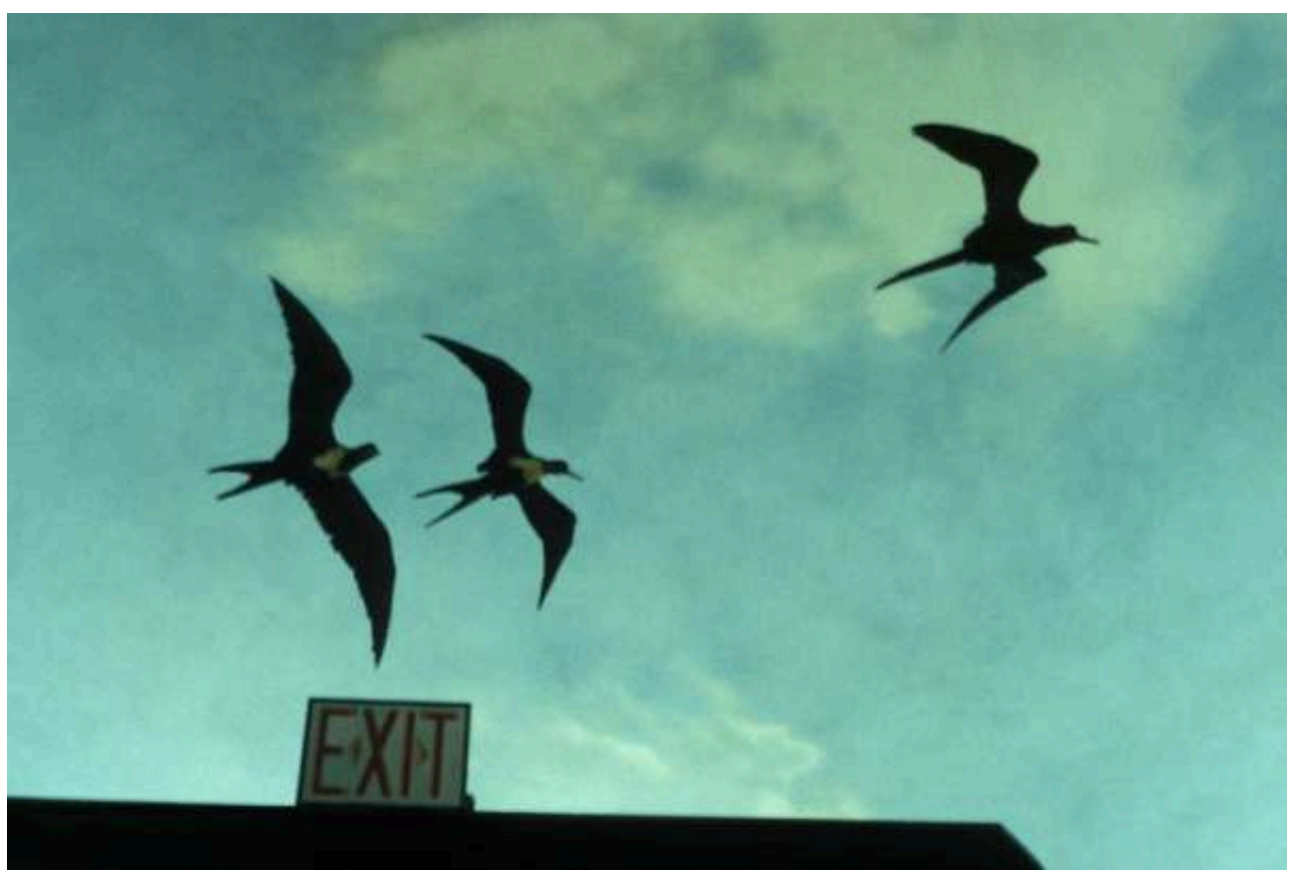

« New York, Sans titre [n.d] », p. 138-9 


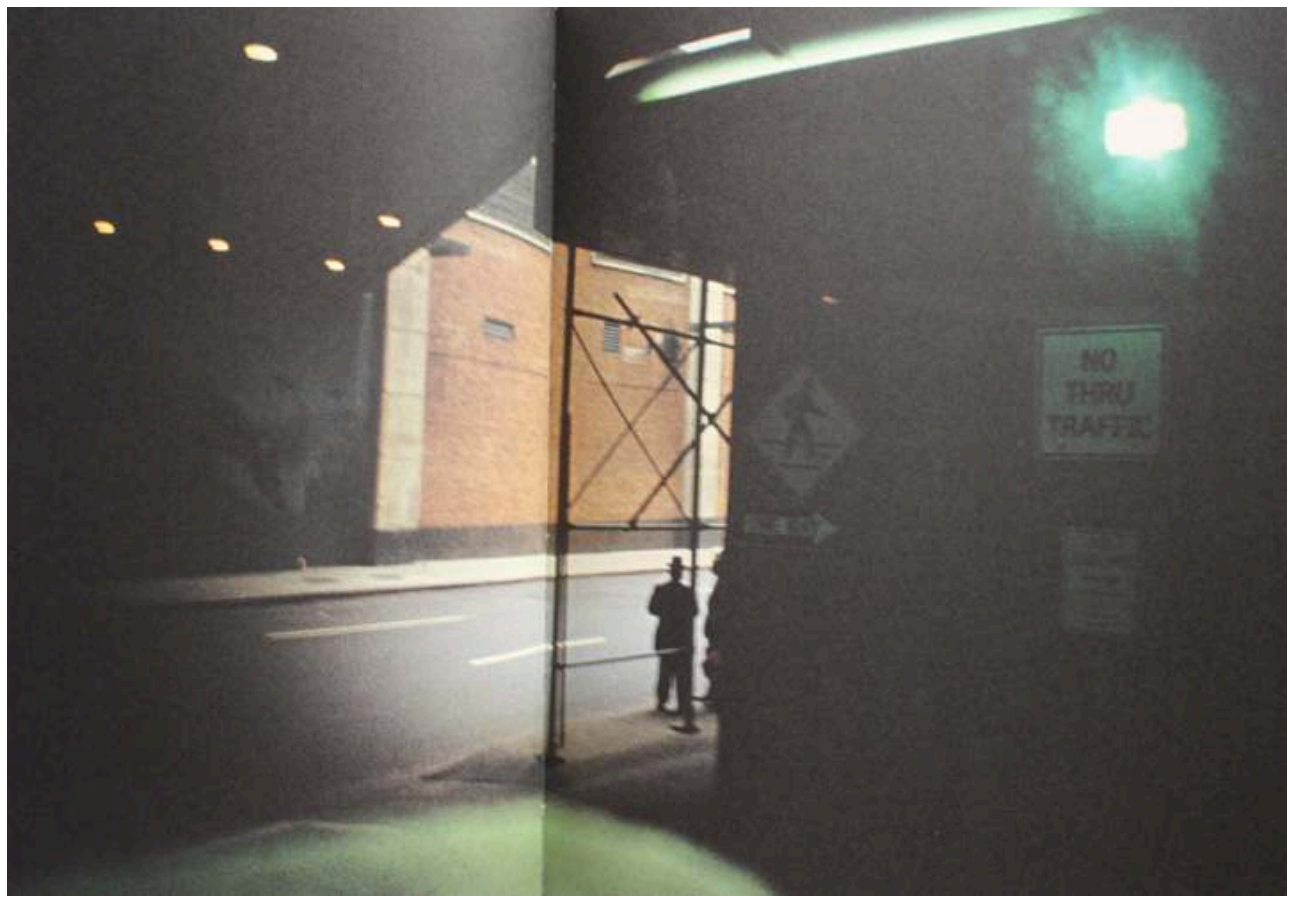

«New York, Sans titre [n.d] », p. 140-1

Dans toutes ces thématiques, l'on trouve des vestiges ou des réminiscences de la vie d'enfance ou de la vie de couple de Dolores Marat, où les phénomènes de rejet et d'abandon sont omniprésents, avec des épisodes de violence qui maltraitent son intimité. Les «bulles» ainsi dépeintes fonctionnent inévitablement comme des projections : la photographe saisit au vol ces images sur son passage comme autant d'autoportraits d'une époque antérieure. D'où cette photographie de la photographe photographiée par un homme dans une voiture (168).

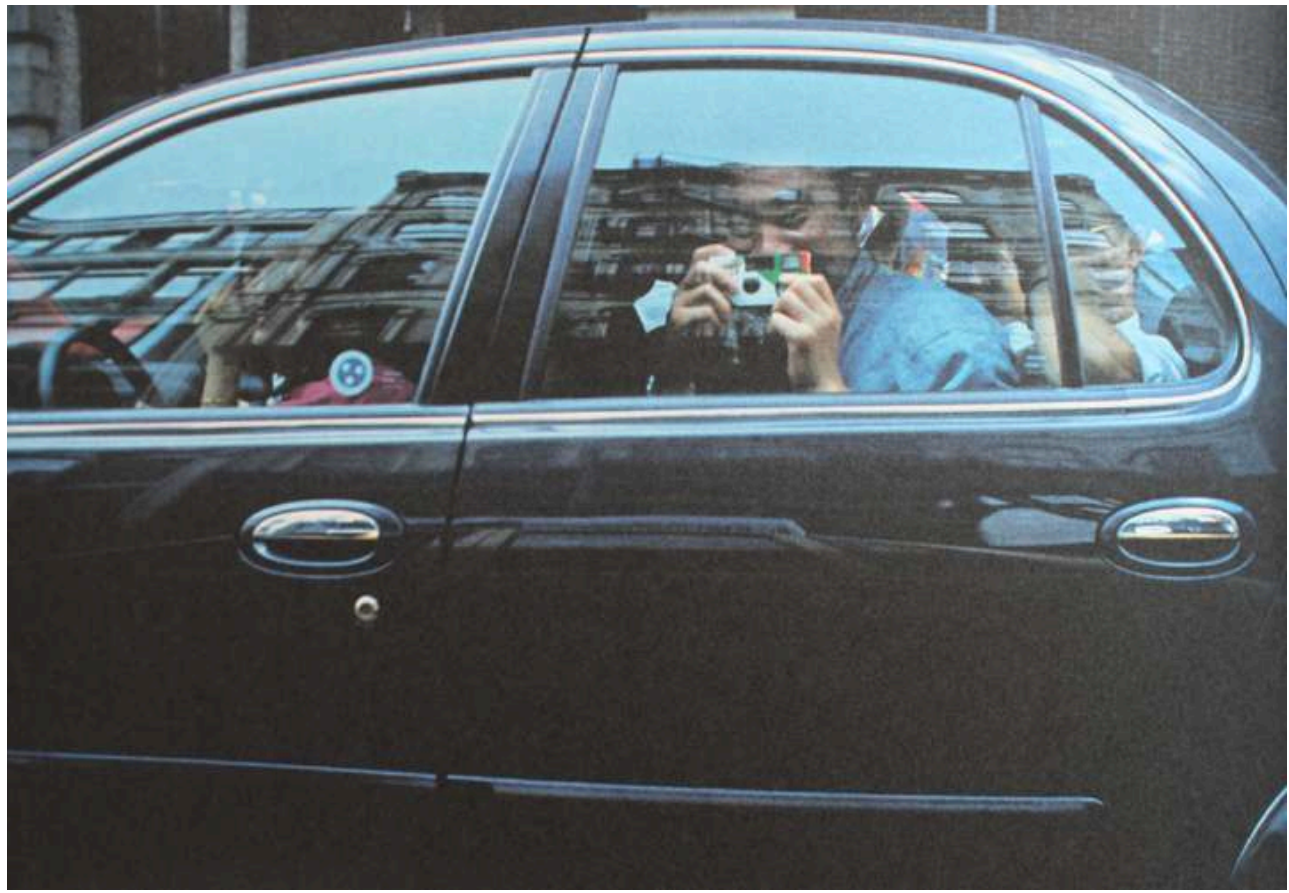

«New York, Sans titre [n.d] », p. 168 


\section{L'indistinction des images} avant du grain, de la matérialité du médium dit en contrepoint l'immatérialité du sujet. La texture cotonneuse confère aux scènes une fragilité, une évanescence, comme si le sujet refusait d'affirmer, péremptoire, sa présence. L'indistinction des images va de pair avec la conscience que le présent ne laisse qu'une empreinte floue, sans véritable matérialité - puisque le présent de la prise de vue est toujours déjà passé et dépassé. Et cette indistinction résulte précisément de ce refus de l'assurance de l'assertion.

Cette indistinction de l'image n'est pas capitulation ni renoncement passif face à l'irreprésentable. Intentionnelle, elle se fait dans le cadre de compositions graphiques étudiées $(45,69,90-91)$ avec une grande attention à l'équilibre des masses et des formes (42-3). L'appareil photo est parfois en butte à des murs comme autant de barrières infranchissables, mais ces murs sont aussi l'occasion de dispositions graphiques intéressantes (197). Les exemples d'arrangements graphiques foisonnent: similitude des lignes de l'architecture et des motifs de la chemise (46-7), croisement de rideaux verticaux et d'une cigarette horizontale (44), centrage d'un éclat du soleil sur une voiture (30-31), reprises des formes d'un obèse dans la rotondité de son crâne et du rouleau qu'il tient à la main, pour ne nommer que ceux-ci (74-75).

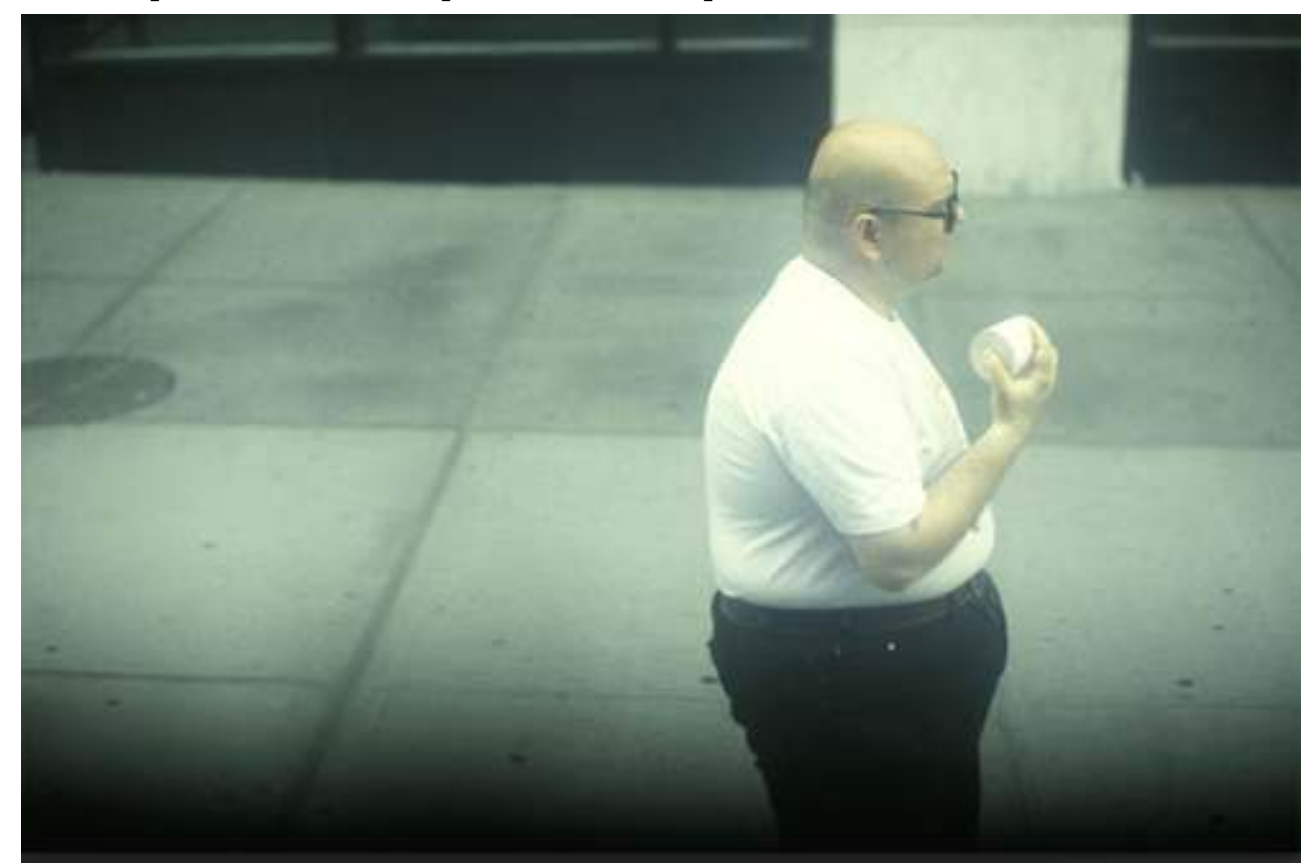

«New York, Sans titre [n.d] », p. 74-5

\section{Le gris diurne}

Avec leurs gros grains, les scènes photographiées semblent traversées d'un souffle qui en retire la solidité et le poids, comme si elles étaient en apesanteur ou en rêve. Et cette impression est exacerbée par l'entre-deux des couleurs, le chromatisme indéfini des scènes. En effet, l'indistinction granuleuse et tamisée est le fait aussi de la couleur, qui est celle d'une atmosphère crépusculaire. Ce gris rend compte de l'effacement, de l'indifférenciation des choses et des personnes. Comme les scènes représentées, les 
couleurs sont livides, exténuées. Absorbées dans leur monde, ces personnes ignorent le chromatisme de son altérité; elles sont absentes à sa coloration. Il serait déplacé que les couleurs fassent intrusion et imposent leur présence là où elles ne sont pas vues. Dolores Marat aime ce gris dans toutes ces nuances. Toutes les couleurs y convergent.

Parfois, les trois couleurs primaires sont présentes, et leur synthèse produit une impression de gris, en lien avec le gris de l'arrière-fond (132-33).

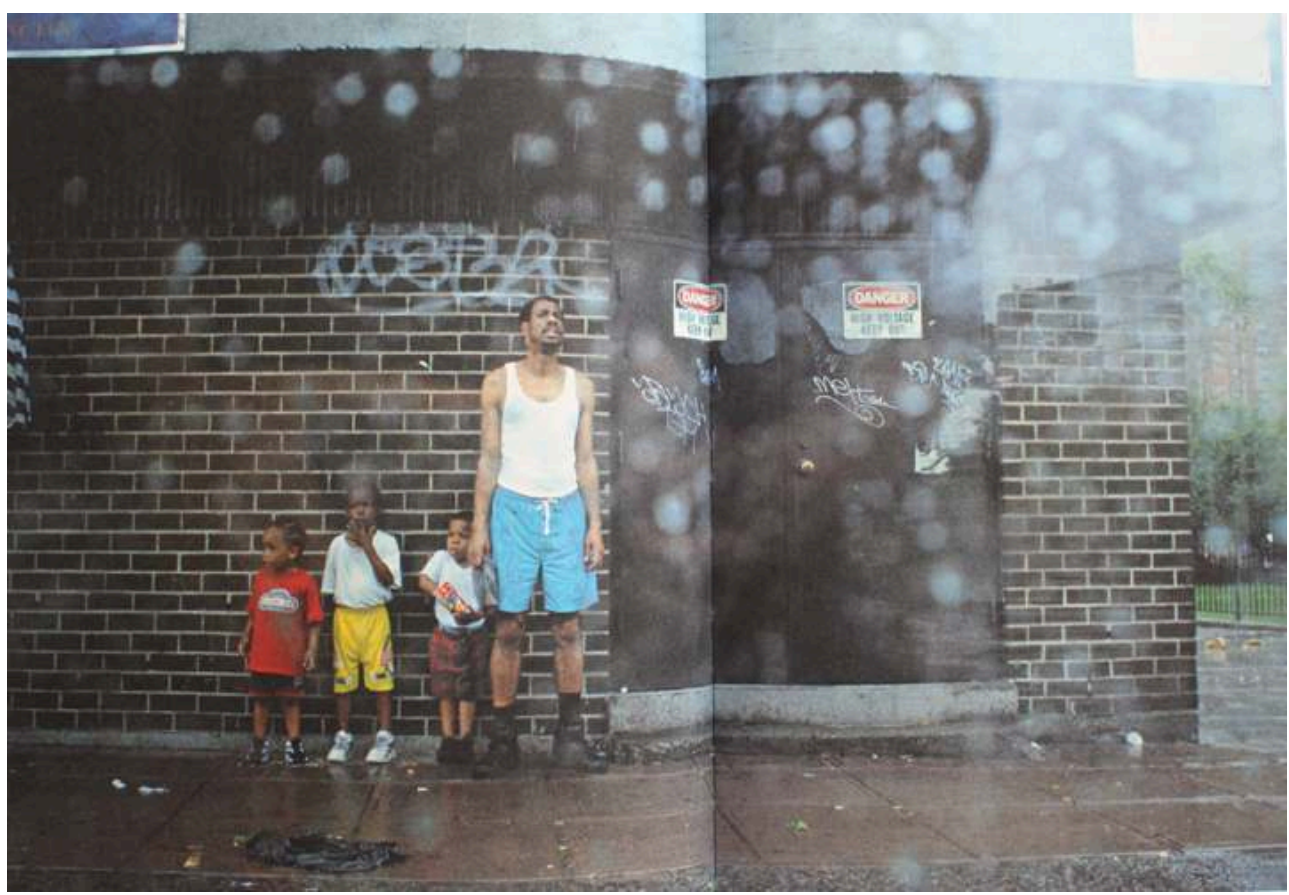

« New York, Sans titre [n.d] », p. 74-5

Dans un autre exemple, un côté bleuté jouxte un côté jaunâtre, avec des taches rouges (86-7). Mais souvent l'image se réduit à une couleur indéfinie, des gammes de gris, qu'il s'agisse du noir et blanc monochromatique d'un câble et de la signalétique parterre (122-3), de la pluie qui fait office de grille et de grisaille (76-77), ou de gris légèrement teintés : le gris pourpre (84-5), violet (124-5), beige (62), bleuté (60-61)... Dolores Marat savoure avec délectation ces camaïeux de gris.

L'on comprend mieux ce gris lorsque l'on voit le gris-brun de l'image qui part en fumée (46-47) : c'est le gris poussière, celui où l'on reviendra, celui de la misère du sort, celui des personnages abandonnés à eux-mêmes, ou des lieux à l'état d'abandon. 


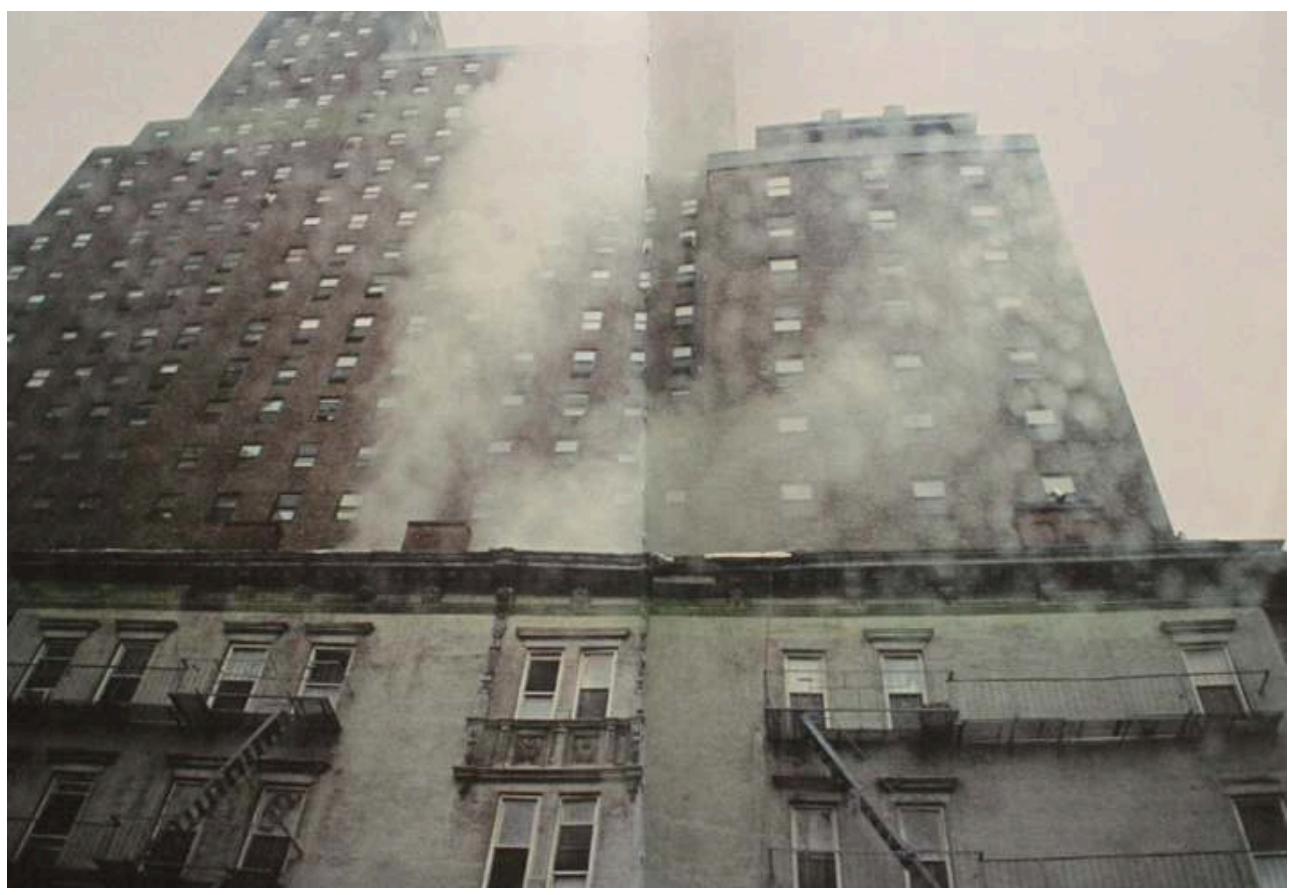

« New York, Sans titre [n.d] », p. 46-7

Ces couleurs fanées, blafardes, passées se rapportent à la thématique du liminal, ou à l'expression fermée de ses sujets, à une pénombre figurée. Ce gris célèbre l'ordinaire (42-3), le non-remarquable, l'effacé - sans jugement aucun. La dérision ne fait pas partie du registre de Dolores Marat. Même les images-clichés (rayonnages de cartes postales avec coucher de soleil, 48) ou les scènes qui pourraient donner lieu à des moqueries (portrait d'un obèse (74-76), personne priant dans un McDonald (33) ne suscitent pas de sentiments corrosifs - à peine une observation étonnée. 


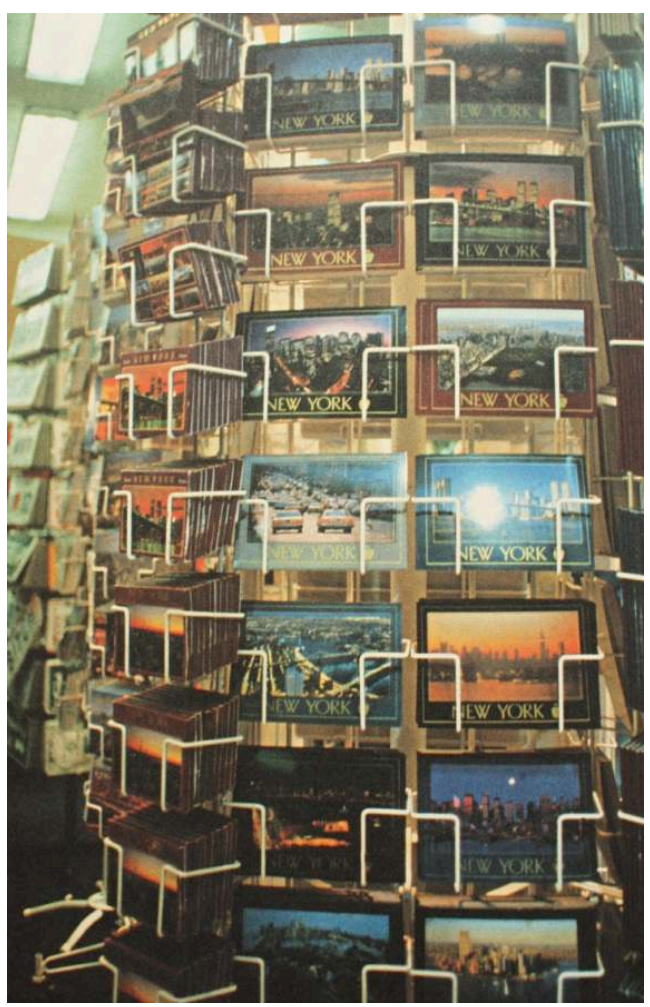

« New York, Sans titre [n.d] », p. 48

Ce gris n'est pas chagrin : il est velouté, et ce grâce au choix du tirage Fresson, tirage très rare au charbon, reconnaissable précisément par son rendu des couleurs. Un des espoirs de Dolores Marat est de photographier, plus tard, la neige, sans doute attirée par son caractère couvrant, ses gros grains et ses nuances de gris ${ }^{6}$.

\section{La couleur nocturne et le kitsch}

28 À l'inverse de ces gris diurnes, le gris que nos yeux voient de la nuit, faute d'avoir les cônes oculaires actifs, est transfiguré en couleurs, de ces couleurs nocturnes que seul l'appareil voit, ce qui confère une somptuosité inhabituelle aux scènes de nuit. Des endroits en d'autres temps délaissés - bars miséreux, croisements de rue, stations de métro extérieures (186-7) ou autres lieux sordides - sont transfigurés par le luxe inopiné des couleurs nocturnes qui s'offrent à l'appareil photo. 


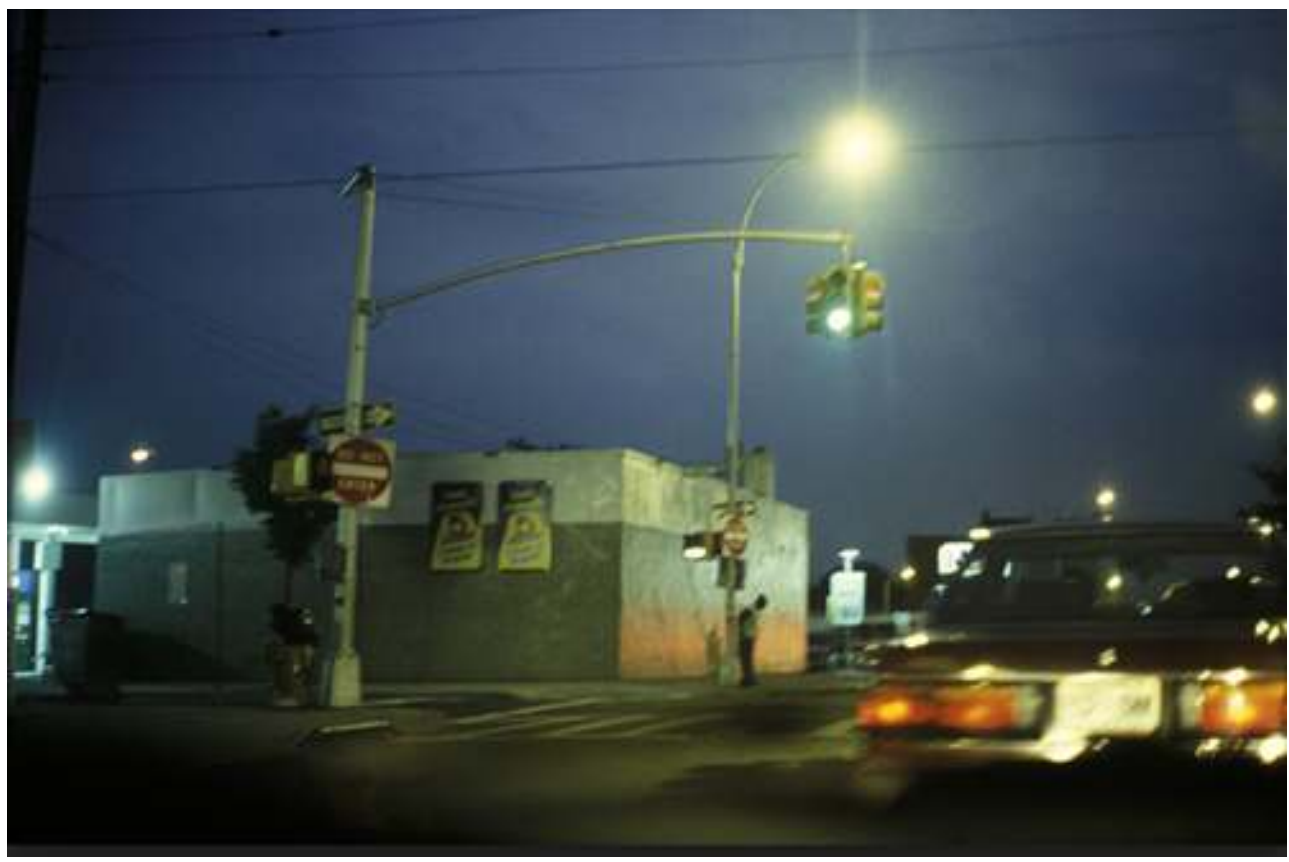

« New York, Sans titre [n.d] », p. 118-9

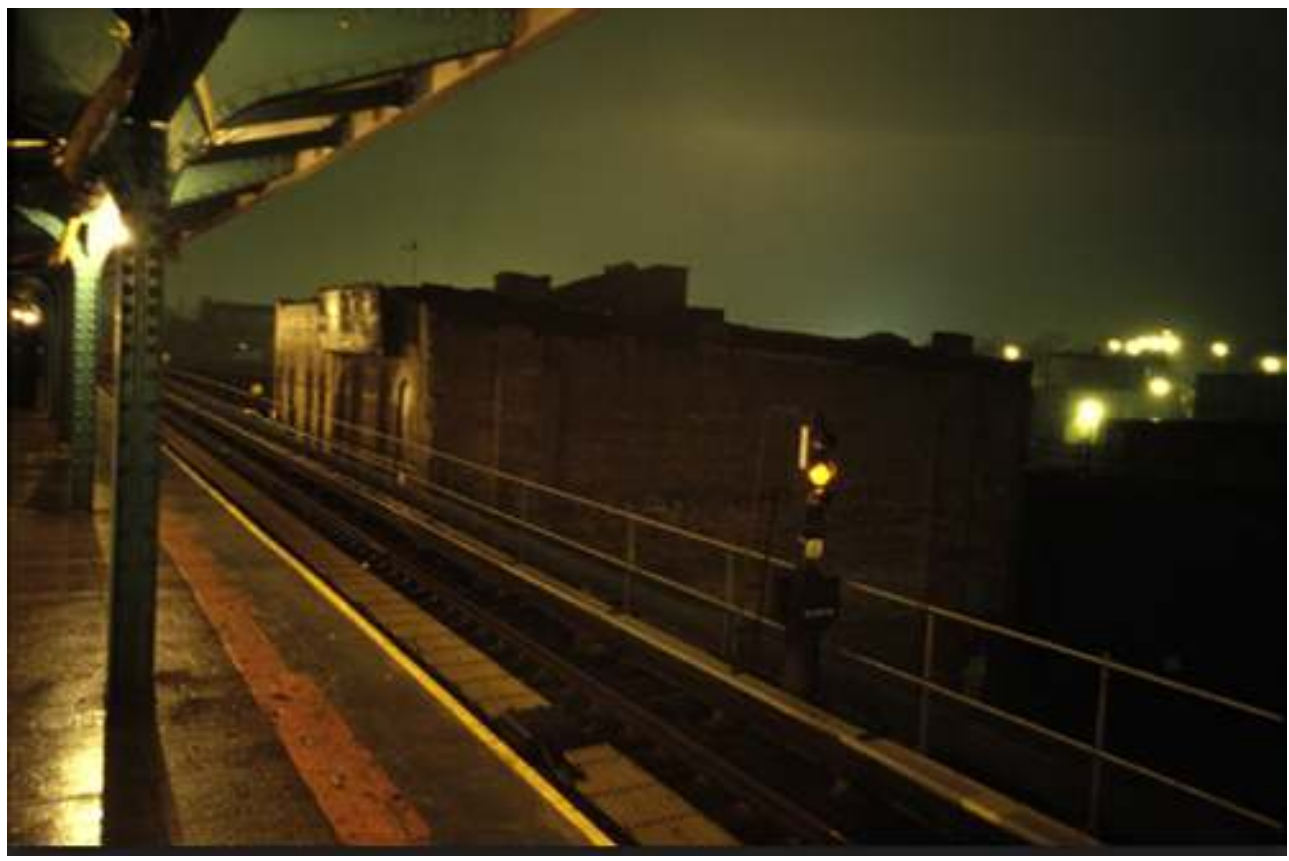

«New York, Sans titre [n.d] », p. 186-7

29 Ainsi, le gris froid ou blond devient argent ou or, comme celui qui laque un immeuble aux escaliers de secours typiquement new-yorkais, et sa lucarne cuivrée (26). Des reflets fauves de la nuit dansent sur une façade (109). Une cour sordide est magnifiée par des jeux de chatoiement or et argent (42-3). Une silhouette dans un tunnel émerge d'une partie verte oxydée où s'étale en lettres cuivrées le mot « Juice » et pénètre dans une partie dorée, jalonnée de flaques réfléchissantes, comme pour mettre en correspondance le jus des couleurs et les reflets mordorés des flaques d'eau (37). 


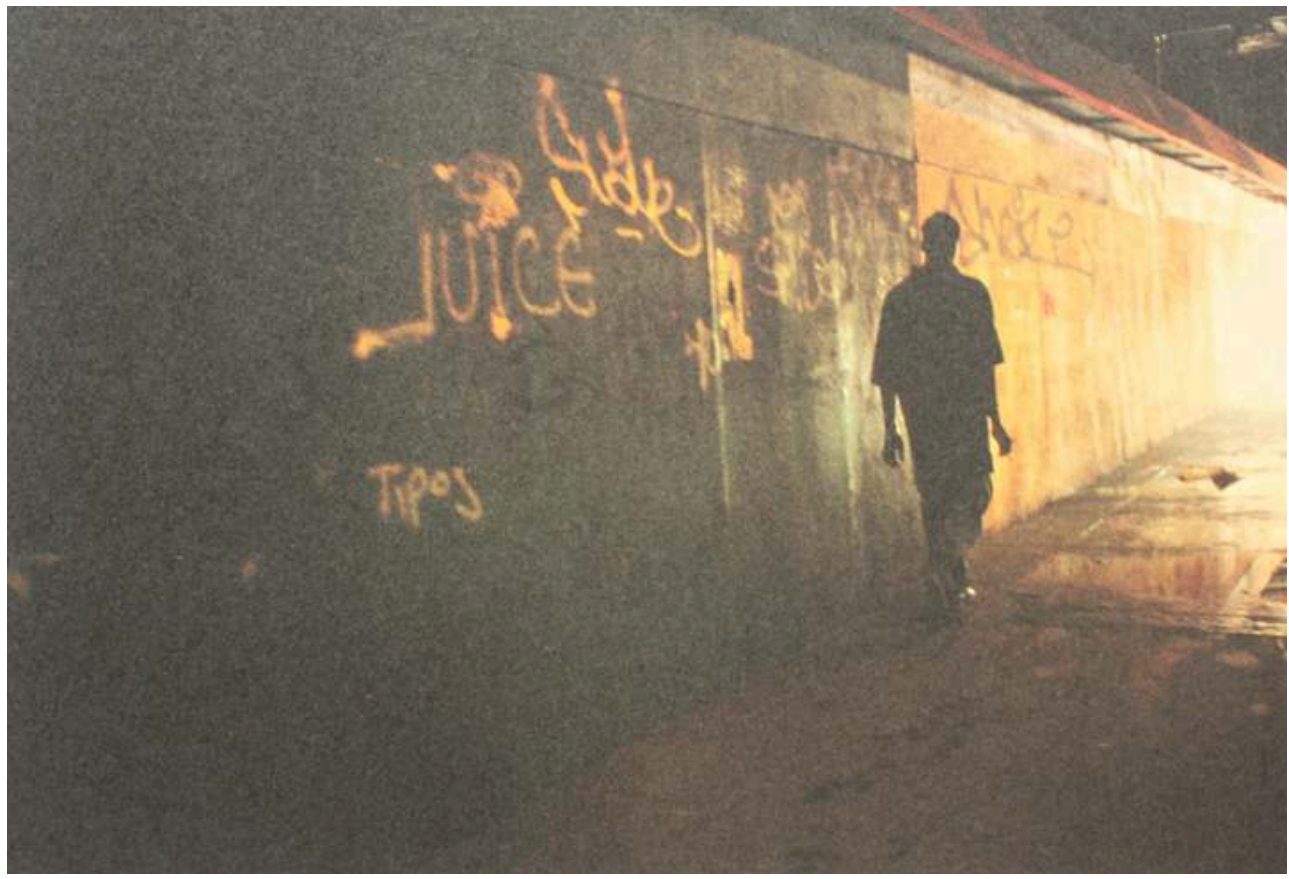

« New York, Sans titre [n.d] », p. 37

30 Dans un autre exemple, les bâtiments de New York se fondent dans la nuit verte, fenêtres éclairées comme autant de bulles orthonormées et scintillantes (102-3) évocatrices du flash photographique.

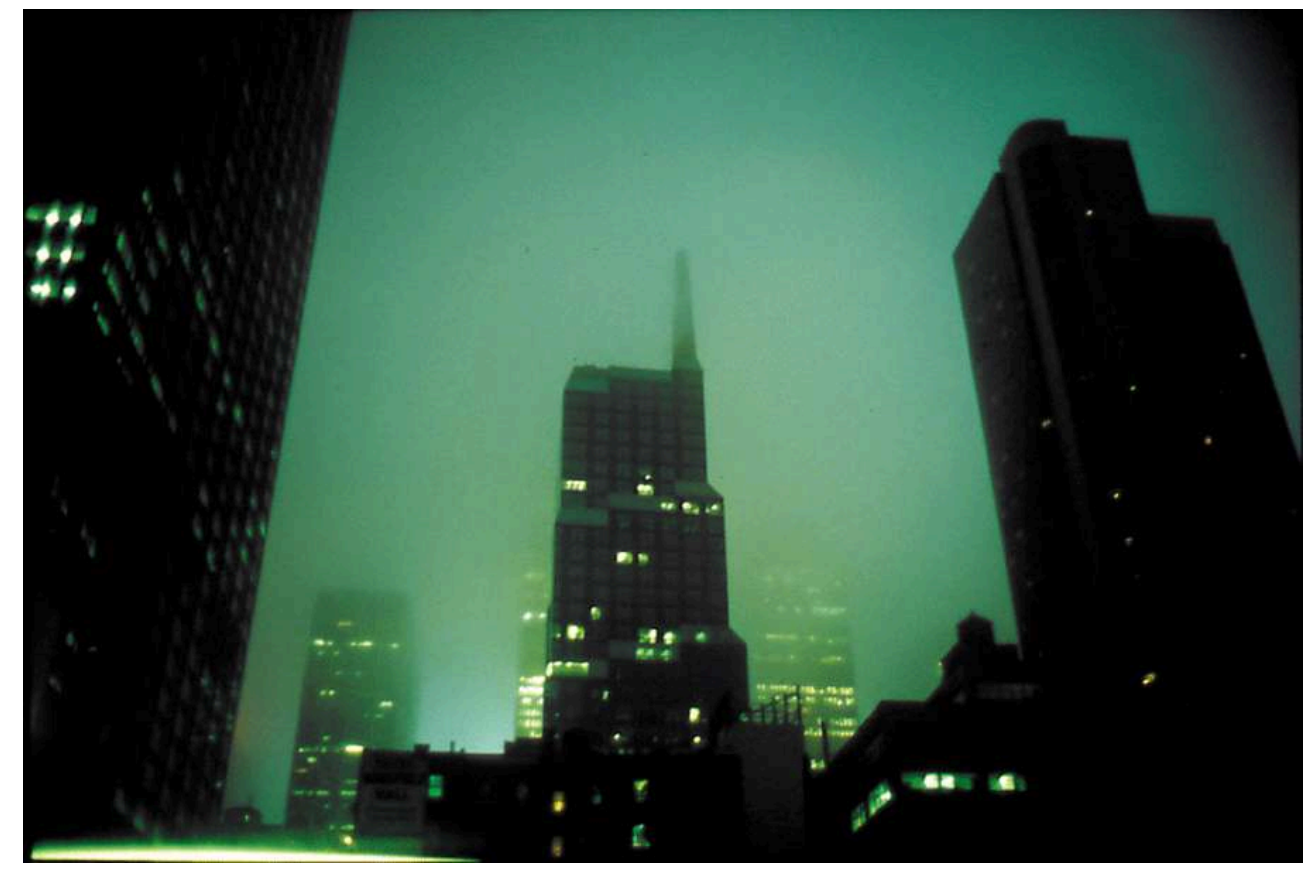

« New York, Sans titre [n.d] », p. 102-3 


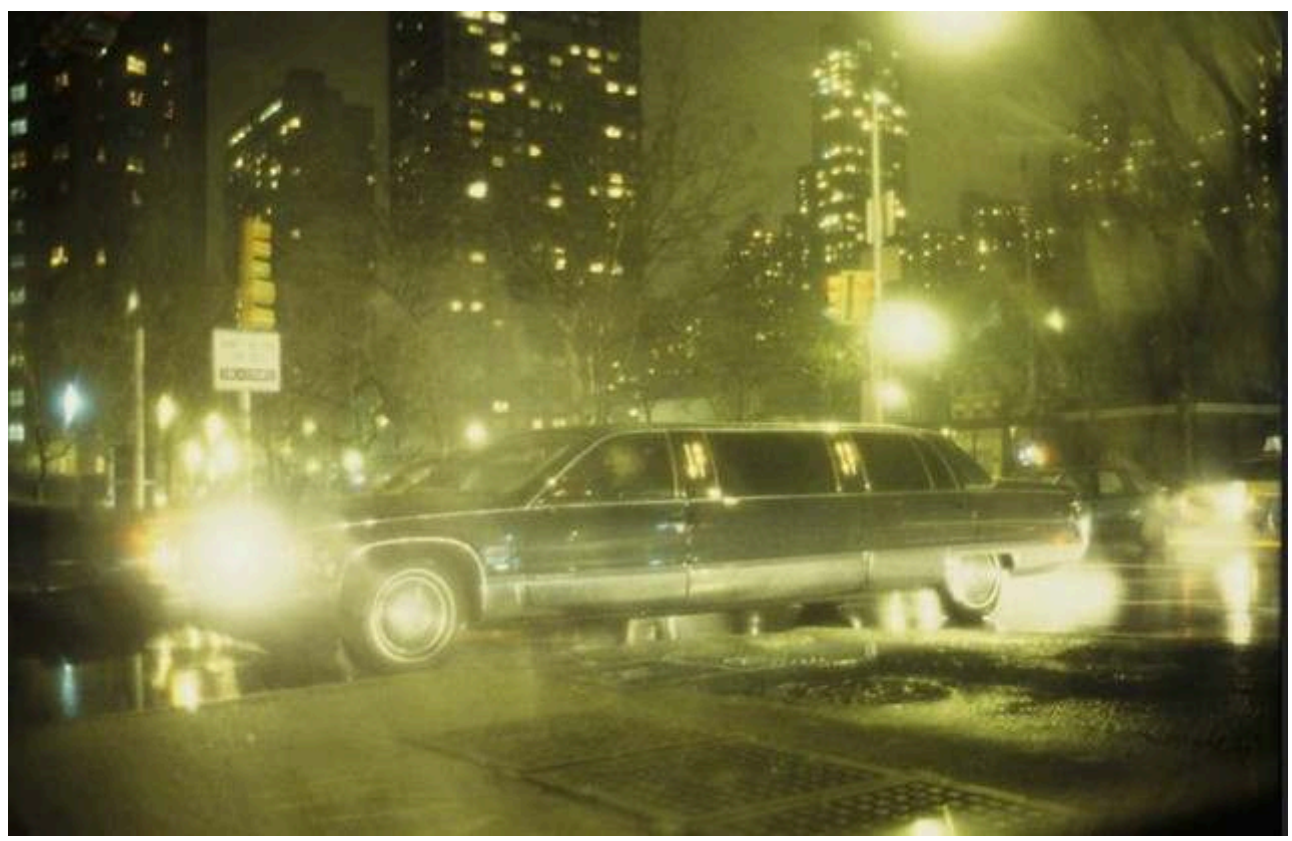

«New York, Sans titre [n.d] », p. 80

31 Les éclairages de ces lieux quelconques sont toujours cheap. Par exemple, la lumière glauque et criarde des néons donne une dominante chromatique jaunâtre tirant sur le vert $(32,161)$.

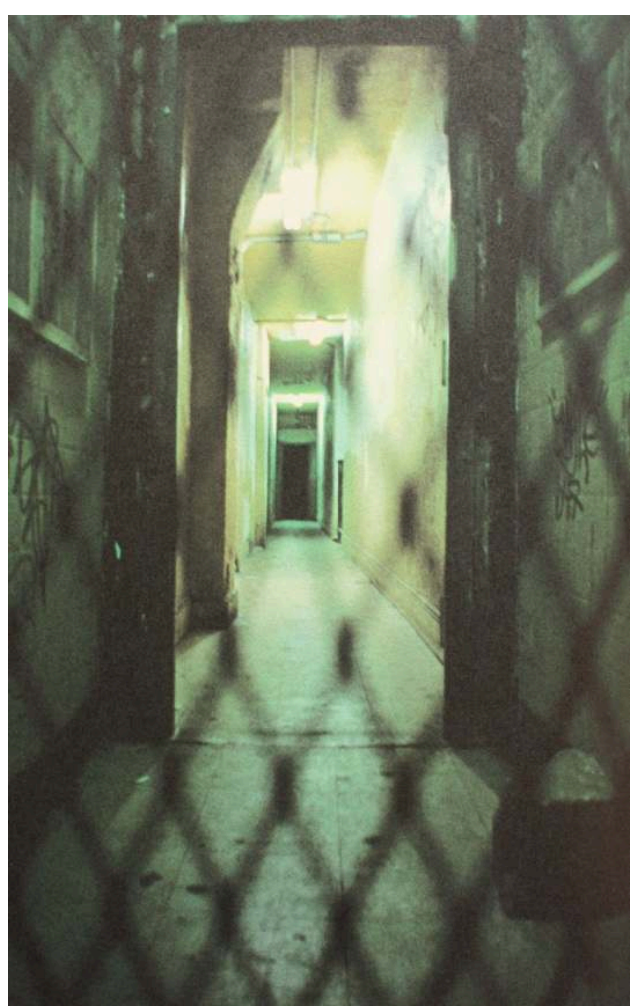

« New York, Sans titre [n.d] », p. 32

32 Cette lumière pauvre est parfois crue, rouge et orange flamboyant dans un bar oublié (25). 


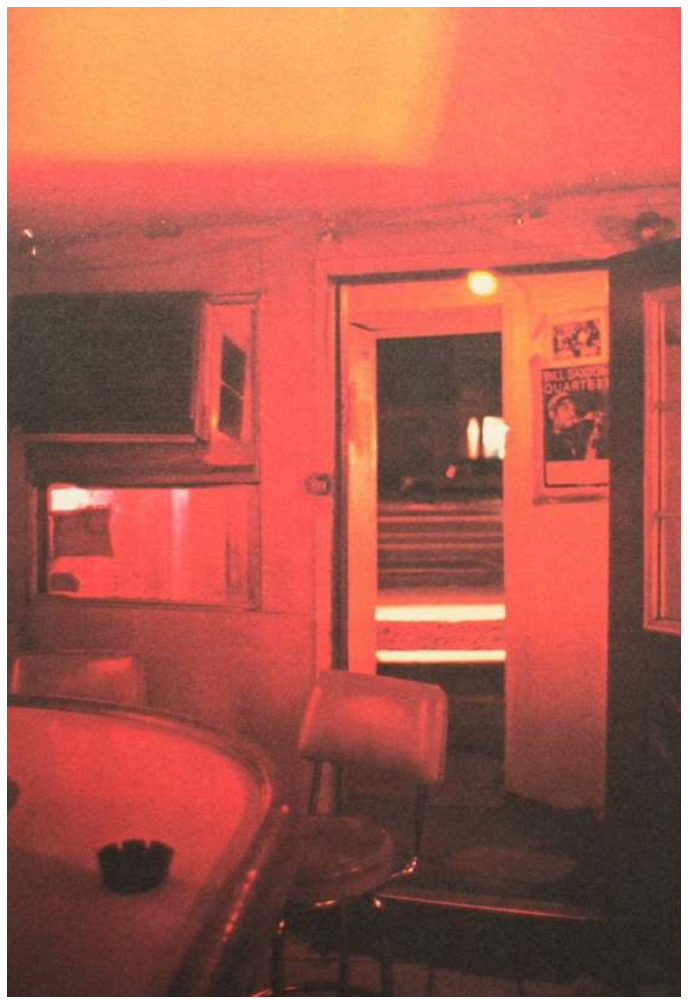

« New York, Sans titre [n.d] », p. 25

Ce chromatisme inhabituel, à rebours du gris diurne, participe d'une autre veine thématique chez Dolores Marat. Cette couleur gueularde donne une présence, une vulgarité, une verve à des lieux déconsidérés. Son caractère tapageur et outré va de pair avec le kitsch, les objets d'art populaire, le monde forain de la nuit, à la fois pouilleux et magique, qui composent un autre courant thématique des photographies de Dolores Marat. Ce monde saltimbanque, prestidigitateur, issu de l'industrie du rêve et de la joie en boîte, fournit à peu de frais une manière d'évasion et d'incandescence dans l'univers terne qu'elle traverse de jour. 


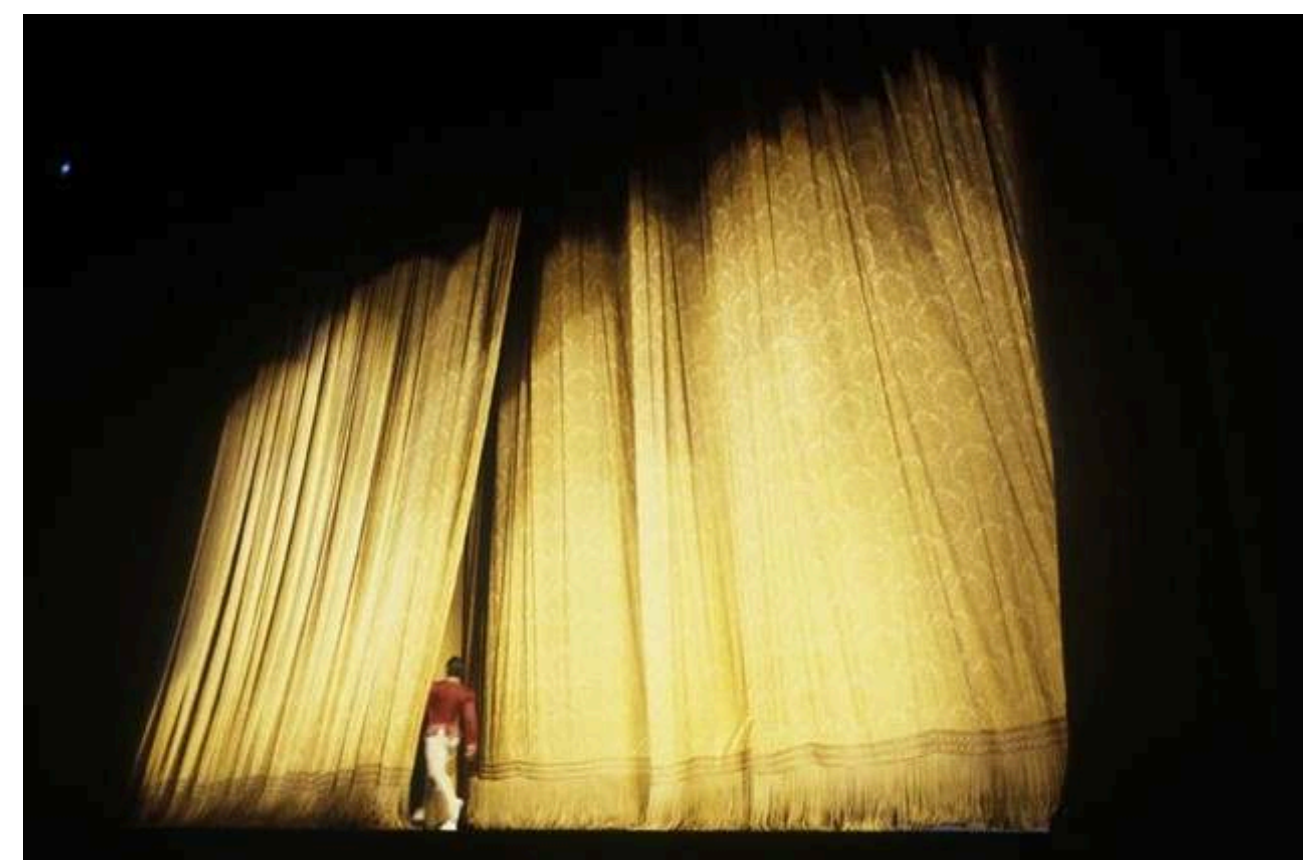

« New York, Sans titre [n.d] », p. 200

34 Il n'empêche qu'ici même le danseur qui disparait derrière le rideau rentre dans sa «bulle » (200), comme dans des draps ou le sommeil de l'image.

\section{Les mannequins et le kitsch}

Les seuls personnages que Dolores Marat s'autorise à photographier frontalement sont des personnages réifiés, littéralement figés dans leurs bulles: des mannequins en celluloïd des vitrines (peut-être en référence au Paris d'Atget ou de Brassaï), réminiscences d'anciennes commandes ${ }^{7}(62,113,128,164,134,201)$. Parfois, ils sont sous plastique, emprisonnés dans cette bulle étouffante. La photographe ne craint pas leur regard. Elle a une tendresse pour ce kitsch avec lequel elle fait commerce, et son attirance s'étend à d'autres objets de pacotille: statue issue de la culture populaire religieuse, Vierge Marie en porcelaine (77), diables grimaçants dans les flammes (92), costume de sirène de mauvais goût (155), illustration d'un cowboy sur un gilet (156-7). 


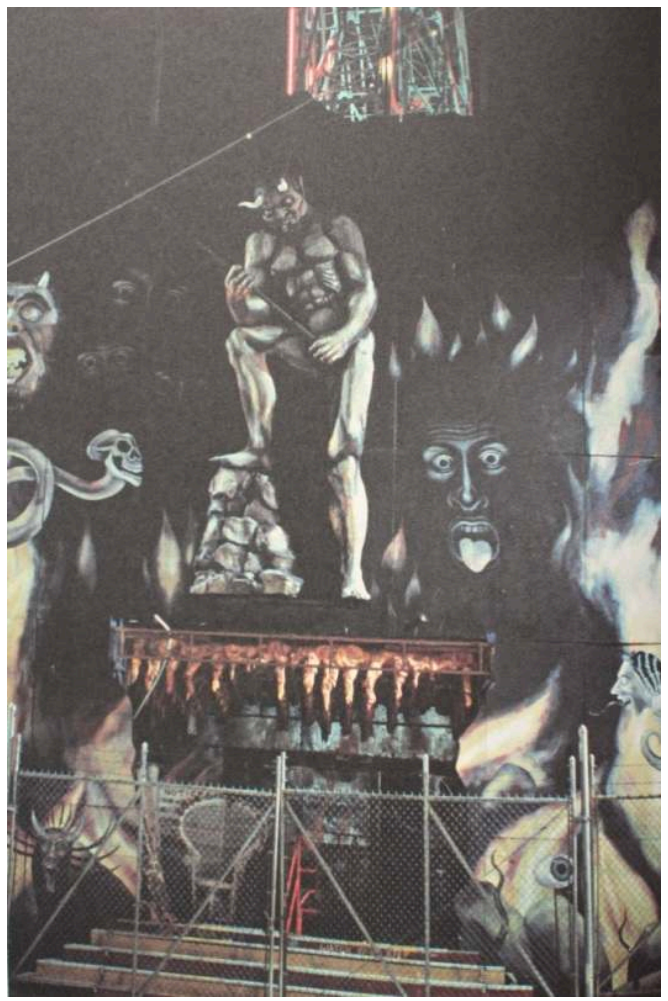

«New York, Sans titre [n.d] », p. 92

Elle s'amuse avec le burlesque lorsqu'elle photographie un mannequin en demi-écorché couvert de repérages gradués derrière une vitrine où se trouve un tableau de prix en dollars, surmonté de l'intitulé « Bodywork » (4).

\section{Faire tapisserie : les animaux}

Parfois, son regard se porte sur les animaux. Ceux-ci sont souvent statiques, représentés de profil, et ressemblent à des illustrations naturalistes d'antan, avec des couleurs surannées (38-9). 


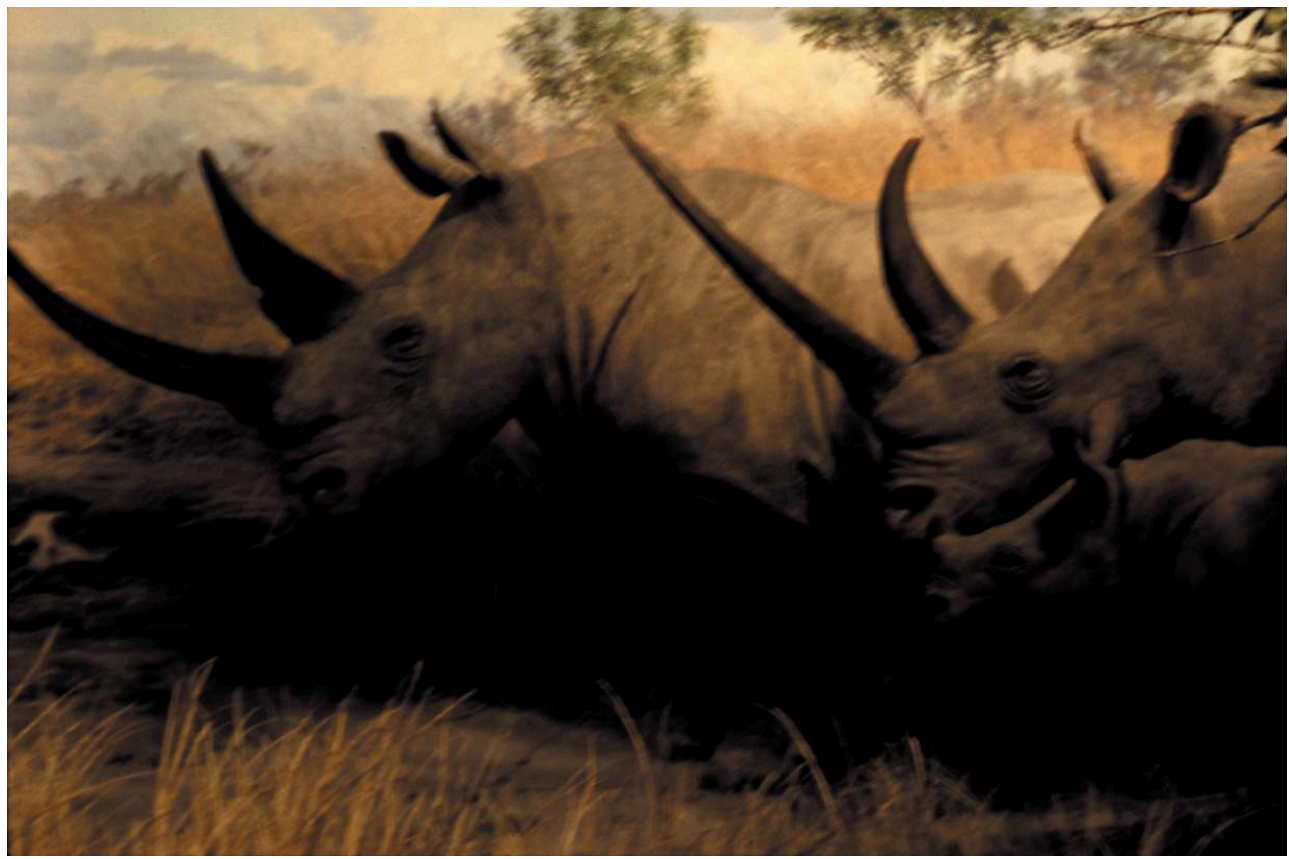

«New York, Sans titre [n.d] », p. 38-9

Des girafes sont représentées devant un décor peint tel a "yellow wallpaper », comme si elles allaient bientôt en faire partie (165).

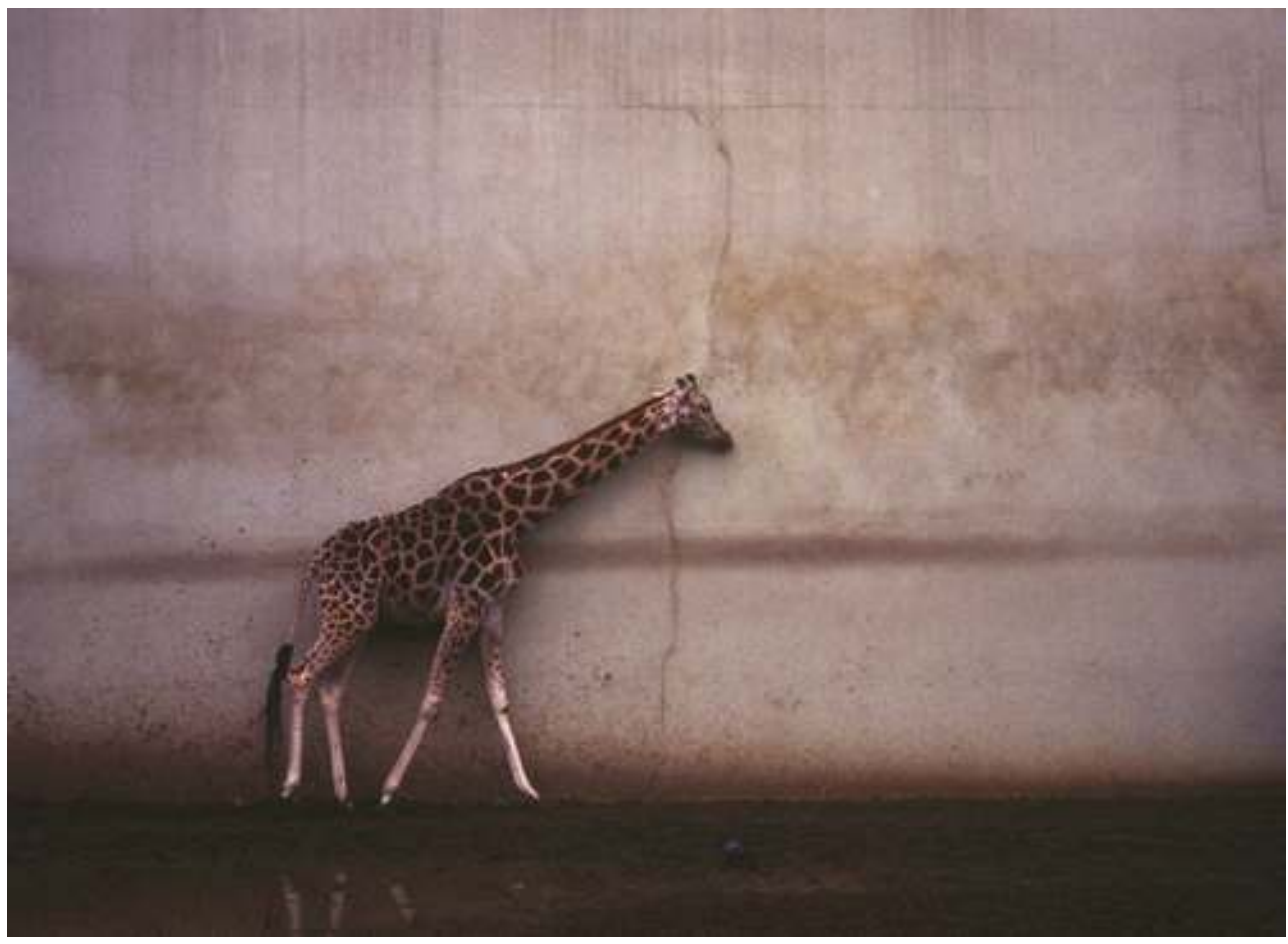

«New York, Sans titre [n.d] », p. 165

Les animaux font tapisserie. Les instincts sauvages sont éteints chez eux, tout relief ou saillie effacés, ils ne sont pas pourvus de vitalité ; ils ne sont là que pour faire "belle image ». On se souvient que Dolores Marat voulait faire un projet sur les zoos. 


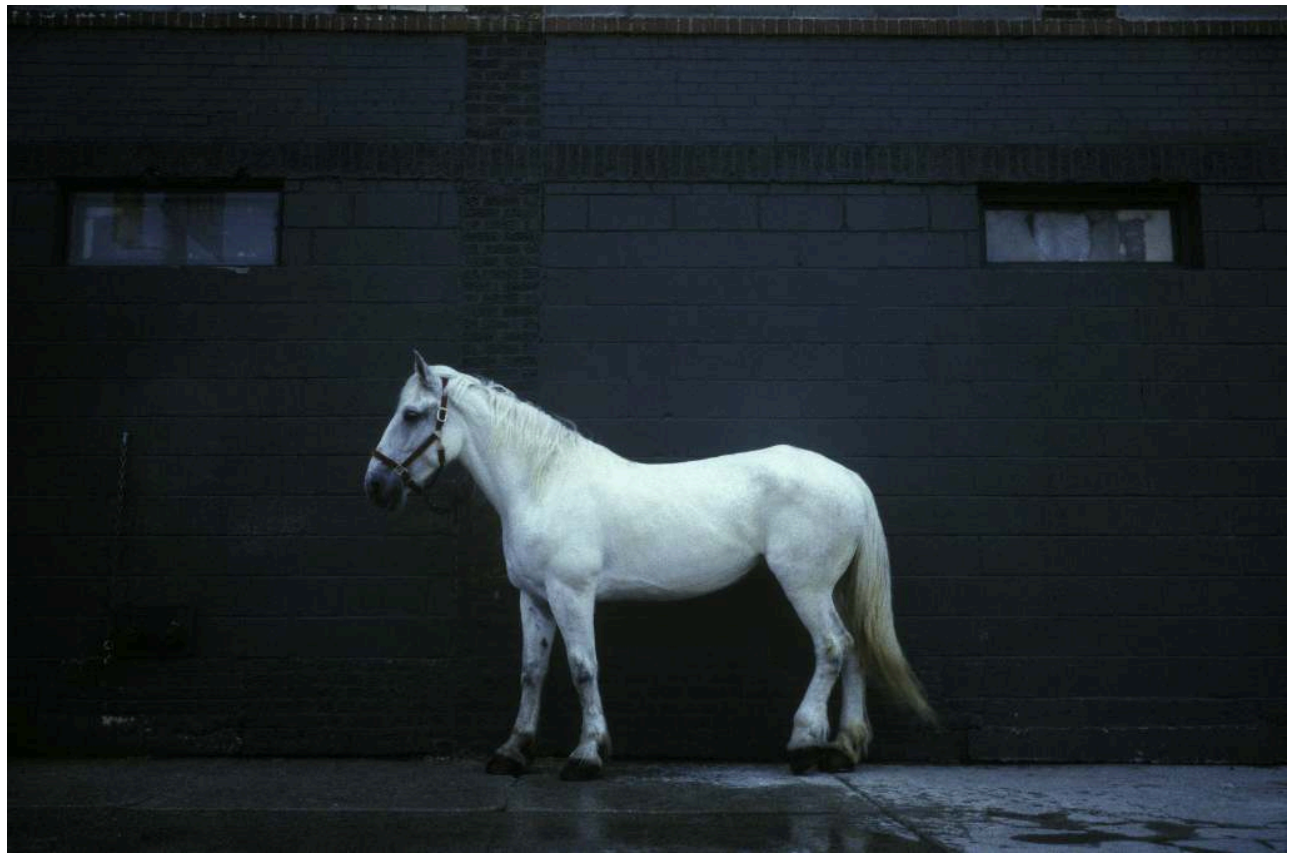

«New York, Sans titre [n.d]», p. 56

Les seuls animaux expressifs sont des animaux artificiels forains. Contrairement au cheval blanc réel de profil sur un fond anthracite $(56,182-3)$, certes beau mais immobile, un cheval de manège luisant hurle, emprisonné dans sa carcasse de plastique (97).

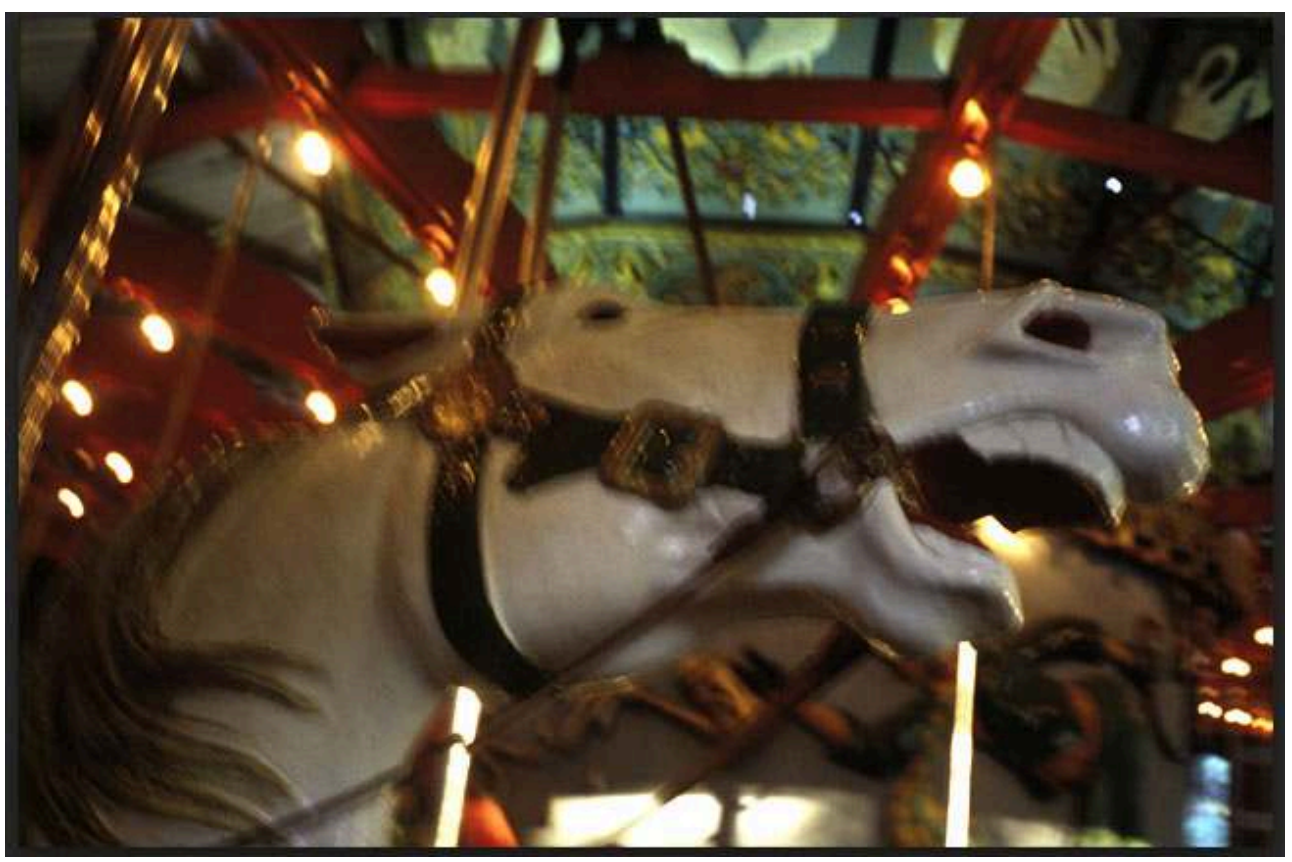

« New York, Sans titre [n.d] », p. 97

41 De même, sur la page de couverture, les gueules de la série des lions illustrés s'ouvrent pour lancer un cri muet. 


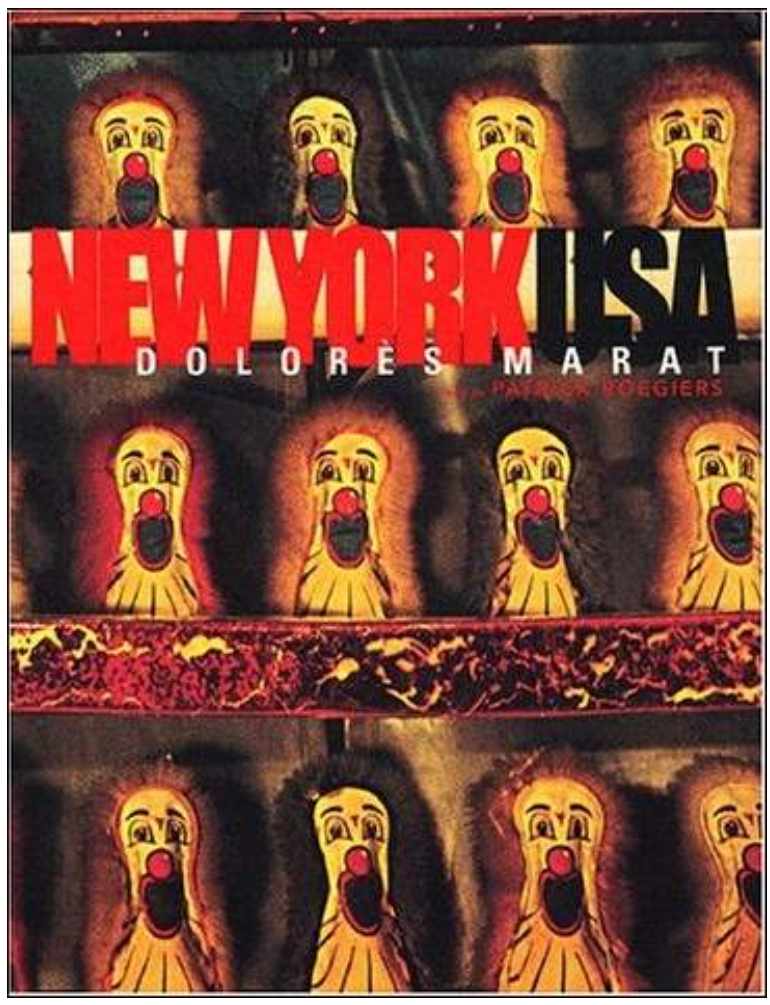

« New York, Sans titre [n.d] », page de couverture

\section{Garder la distance}

\section{L'objet du premier plan}

En général, au premier plan, apparaît une forme d'obstacle montrant que la photographe se situe dans un espace autre que la scène représentée. Cette forme, rarement identifiable, est souvent perdue dans le flou antérieur à la profondeur de champ (82-3, 33). Qu'il s'agisse d'alvéoles de grillage (32, 84-5, 170-171, 176), de poutres métalliques, de pilier, de rampe, de barreau (178-9), de pont en Y (129), de pluie (132-3), ces formes sont toujours peu distinctes (94-5). Ce premier plan est parfois d'un symbolisme très marqué : ainsi la croix (des barreaux de la fenêtre du bateau) devant la Statue de la Liberté (188). 


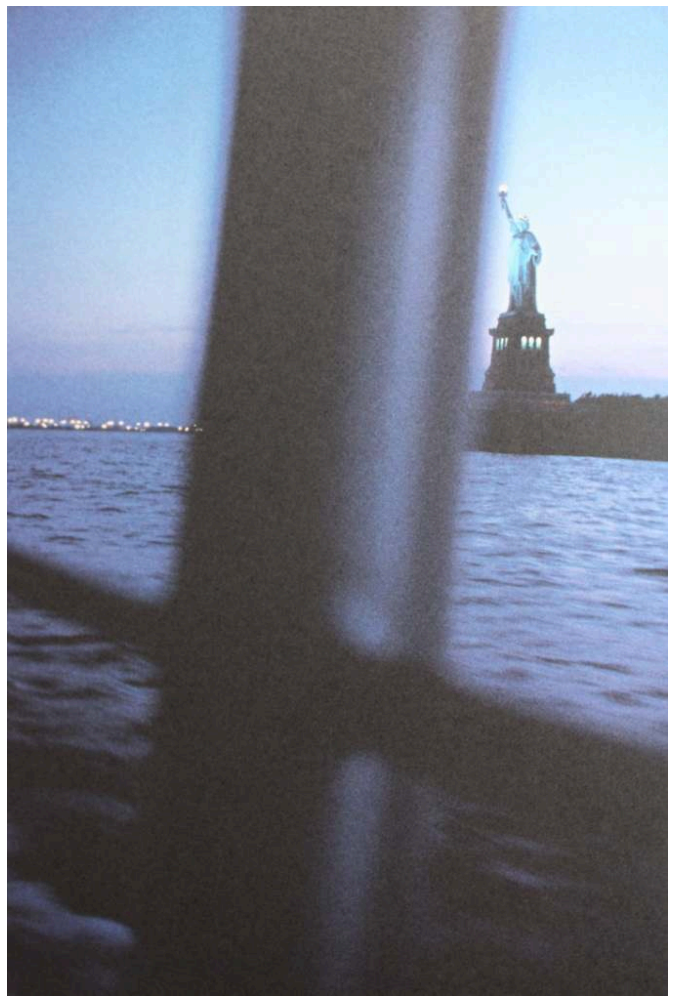

« New York, Sans titre [n.d] », p. 188

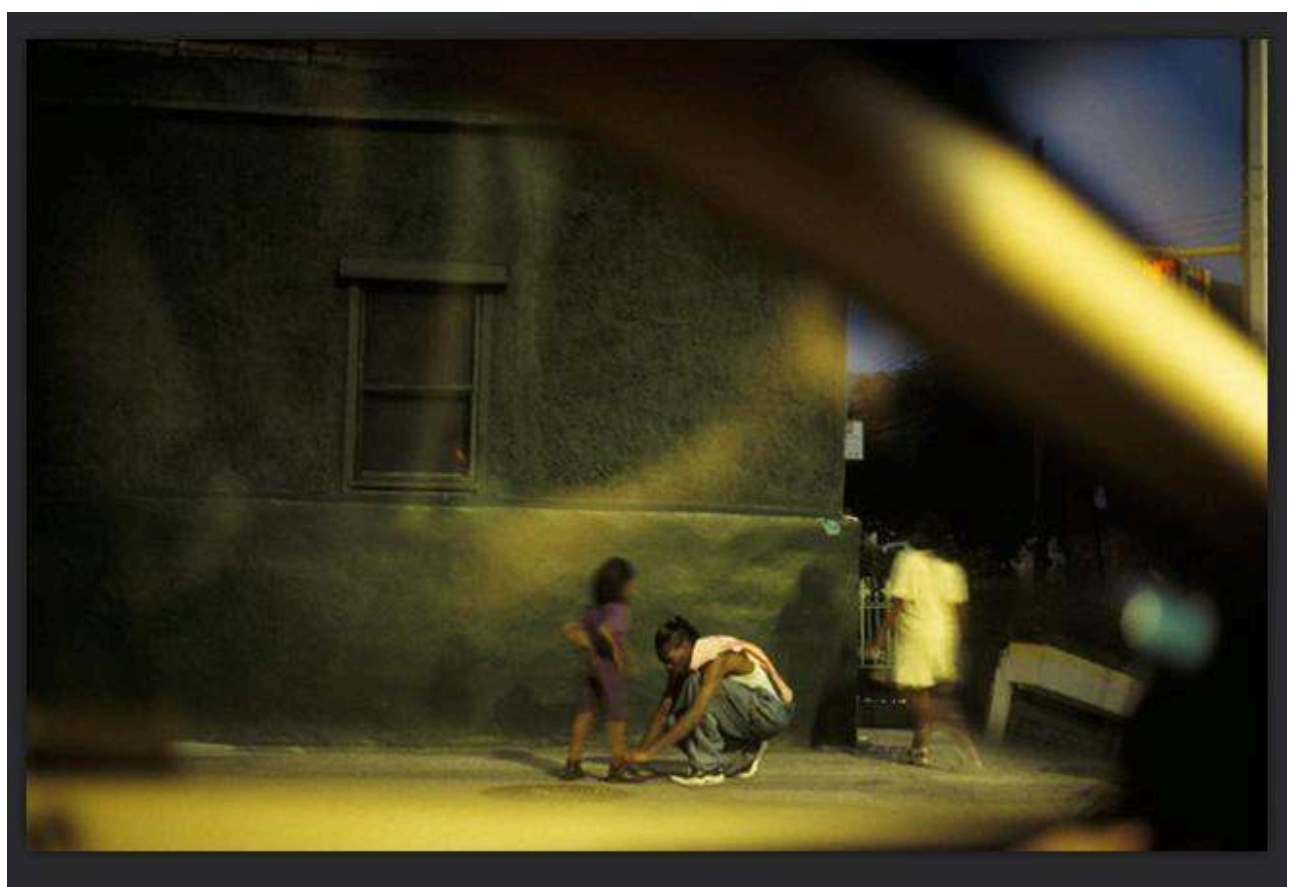

« New York, Sans titre [n.d] », p. 42-3

Ces objets en premier plan permettent de recadrer les plans (100, 42-3), d'apporter de nouvelles touches de couleurs, mais surtout de marquer physiquement la séparation de la scène visée d'avec la photographe. Ils permettent aussi de redoubler le cadre et de faire apparaître le point de vue. La scène reste extérieure $(89,100)$. À cela, deux raisons. D'abord, la photographe est protégée par cet objet, quand ce n'est pas aussi par le dos 
des personnages : elle n'est pas engagée dans un face-à-face. De plus, ce premier plan qui bloque l'accès aux personnages dit, de la distance, sa nécessité.

\section{La distance et le respect}

Dolores Marat passe inaperçue; il est très rare qu'elle soit repérée. Elle n'a pas l'apparence d'une photographe professionnelle, dit-elle, et tente de se mêler au décor. Par ailleurs, elle travaille avec un objectif de 28 ou $35 \mathrm{~mm}$, jamais avec une longue focale. Si elle s'abrite derrière ce premier plan, si elle se tient à distance des personnages, c'est que la discrétion est de mise mais aussi essentielle. Si cet élément qui s'interpose donne la mesure de la distance entre les espaces, c'est que les deux réalités - celle de la photographe et celle des personnages photographiés - ne peuvent fusionner. Dolores Marat a trop de respect pour les personnages qu'elle photographie pour prétendre à une quelconque empathie artificielle.

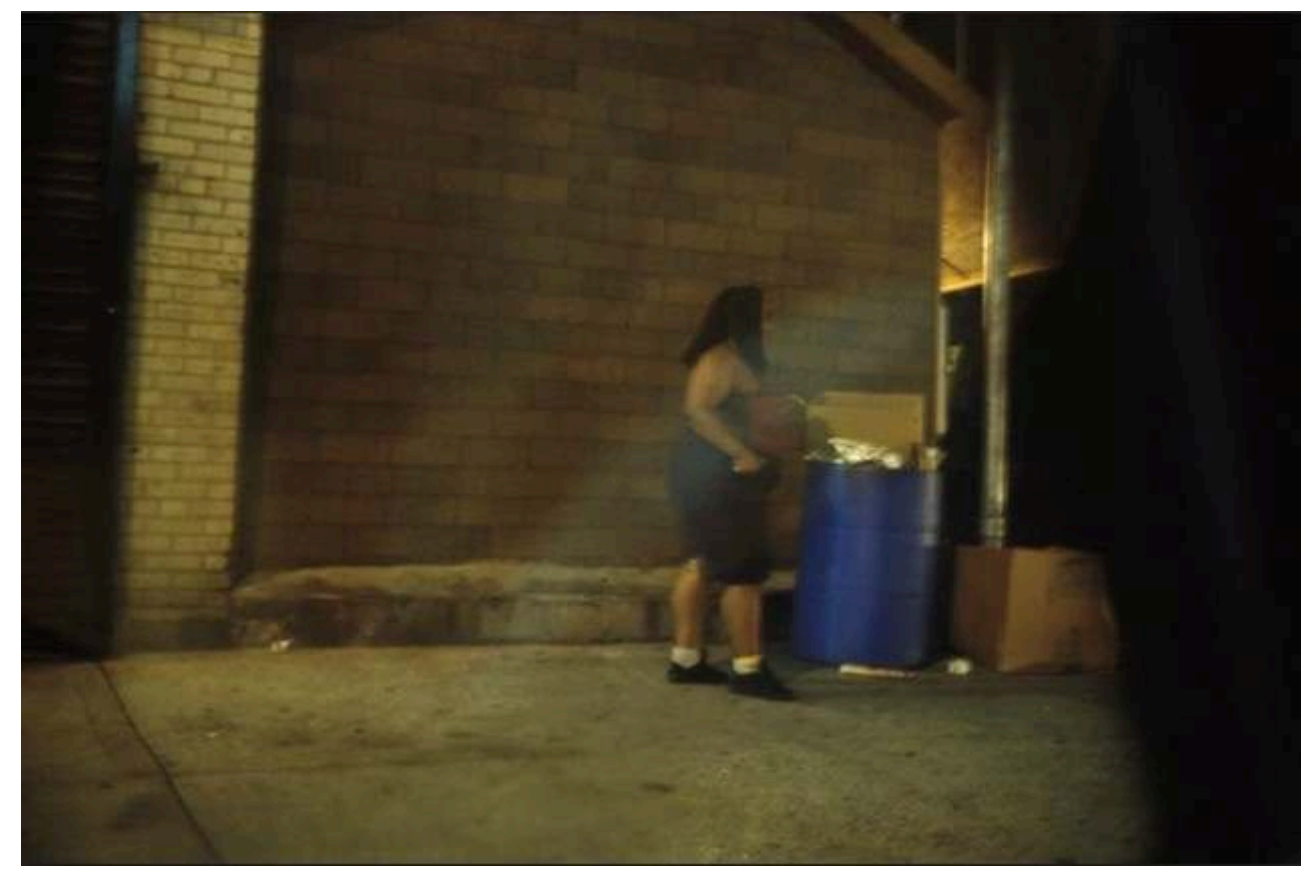

« New York, Sans titre [n.d] », p. 178-9

Des personnages, elle ne peut avoir qu'une perception furtive, émue; elle ne feint pas la compréhension intime et ne renie pas la distance qui les sépare. Dolores Marat ne souhaite pas faire intrusion, ni physique ni morale. Elle évite de juger et d'avilir. Dans le métro, deux personnages sont photographiés en contre-plongée pour des raisons de discrétion dans la prise de vue certes, mais aussi pour ne pas les diminuer même s'ils sont désœuvrés et passifs, en situation d'attente (82-3). 


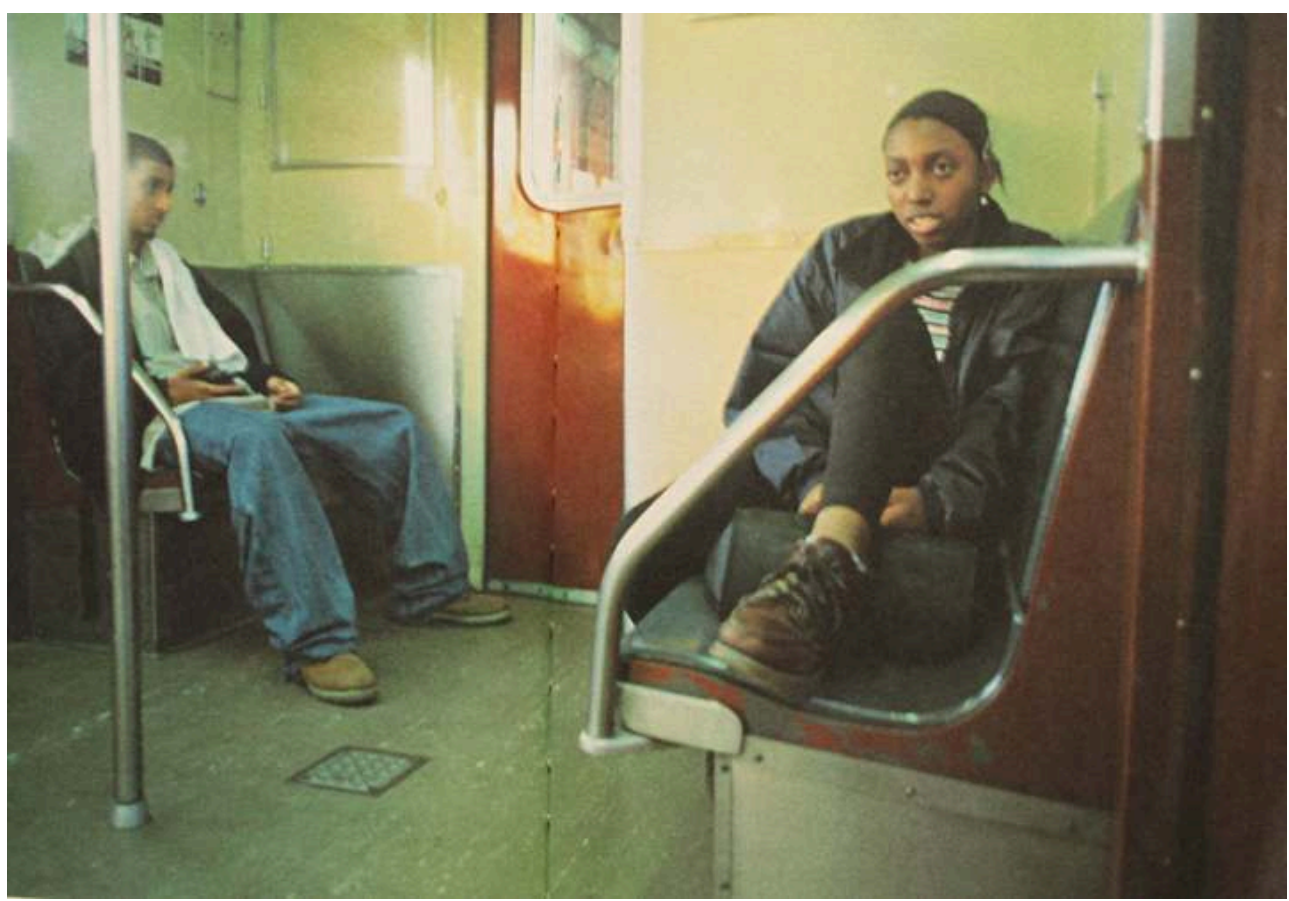

« New York, Sans titre [n.d] », p. 82-3

Par ailleurs, l'impression de voile que donne le tirage Fresson contribue au cloisonnement de la scène qui échappe à une perception nette. La facture nébuleuse des photos et l'indistinction du premier plan témoignent paradoxalement de la distinction des êtres. De surcroît, le tirage Fresson rappelle les vieux papiers brouillés par la patine du temps qui passe, tout comme la mémoire se limite à de vagues impressions floutées, et renvoie ainsi un air de nostalgie. La perception d'autrui est non quelque chose qui apparaît dans une assurance claire, qui sait nommer et dire, mais dans l'humilité du regard qui refuse de trancher. Le personnage doit rester en gros grains, ses limites doivent baver, car ainsi en est-il. Il n'y a pas de mise au point, il n'y a que du doute : Dolores Marat refuse de définir, de figer l'espace vital du personnage ; elle lui laisse son espace, ses marges de liberté, son éloignement. 


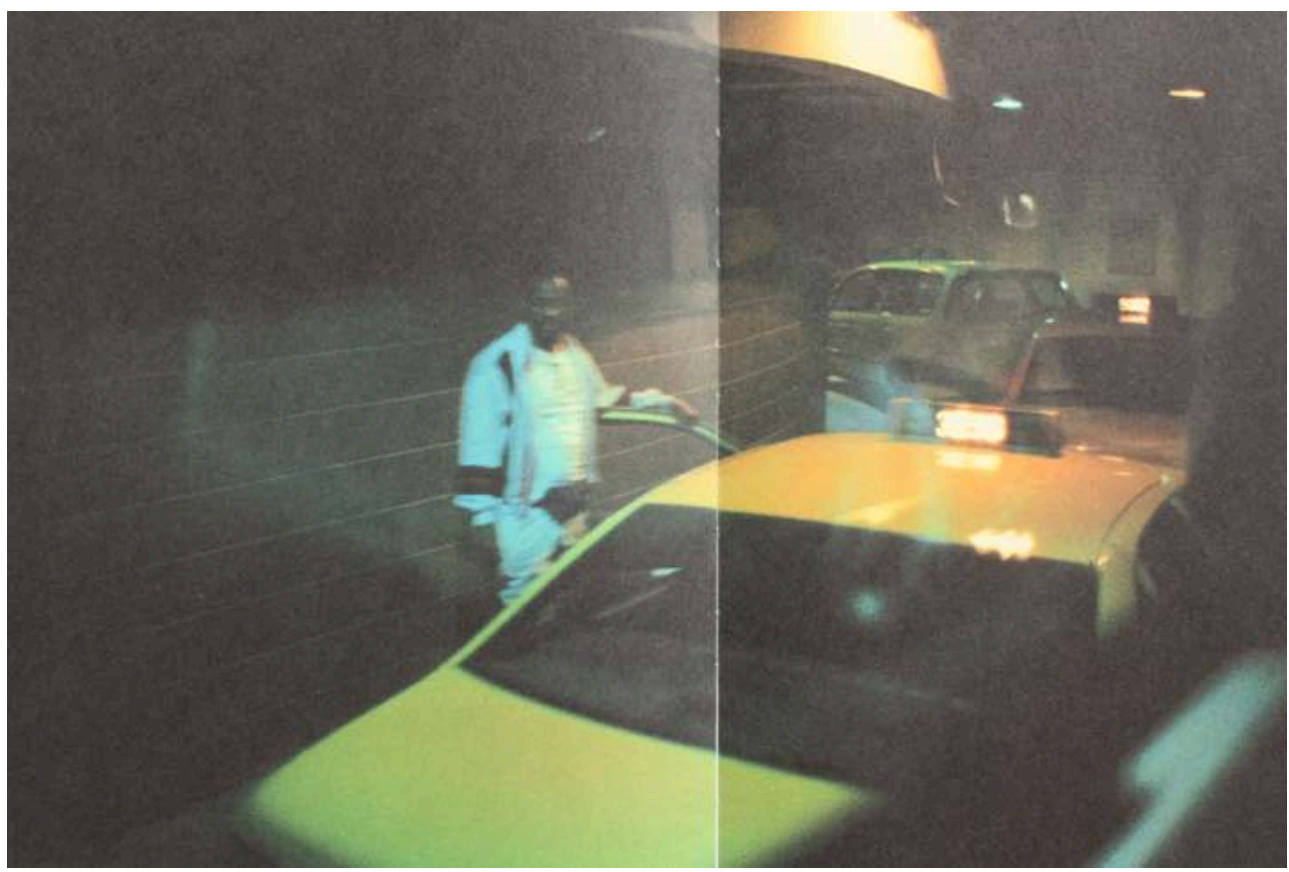

« New York, Sans titre [n.d] », p. 26-7

47 Le refus de cerner, comme dans un aveu que les personnages lui échappent et ne peuvent être saisis clairement par l'appareil de vision, est une forme de respect. L'Autre est une grâce face à laquelle le regard est impuissant, d'où la modestie de ces photographies. Le regard, volontairement incertain, tâtonne. C'est en effet une forme de «tact » : Dolores Marat insiste sur le fait qu'elle prend une photo lorsqu'elle se sent « touchée », et en retour, les tirages Fresson donnent à voir la douceur de leur matière.

Dans un exemple, la photographe est derrière une table, elle-même derrière une chaise dont la partie supérieure du dossier forme un double cœur tranché en deux, elle-même derrière un homme de dos, accoudé, et pensif. Tout est là : la froideur chaleureuse de la scène, la séparation physique de la photographe et du personnage par ces plans successifs, ce double cœur derrière lequel l'homme, perdu dans ses pensées, peut-être abattu, est discrètement magnifié par une contreplongée (49). 


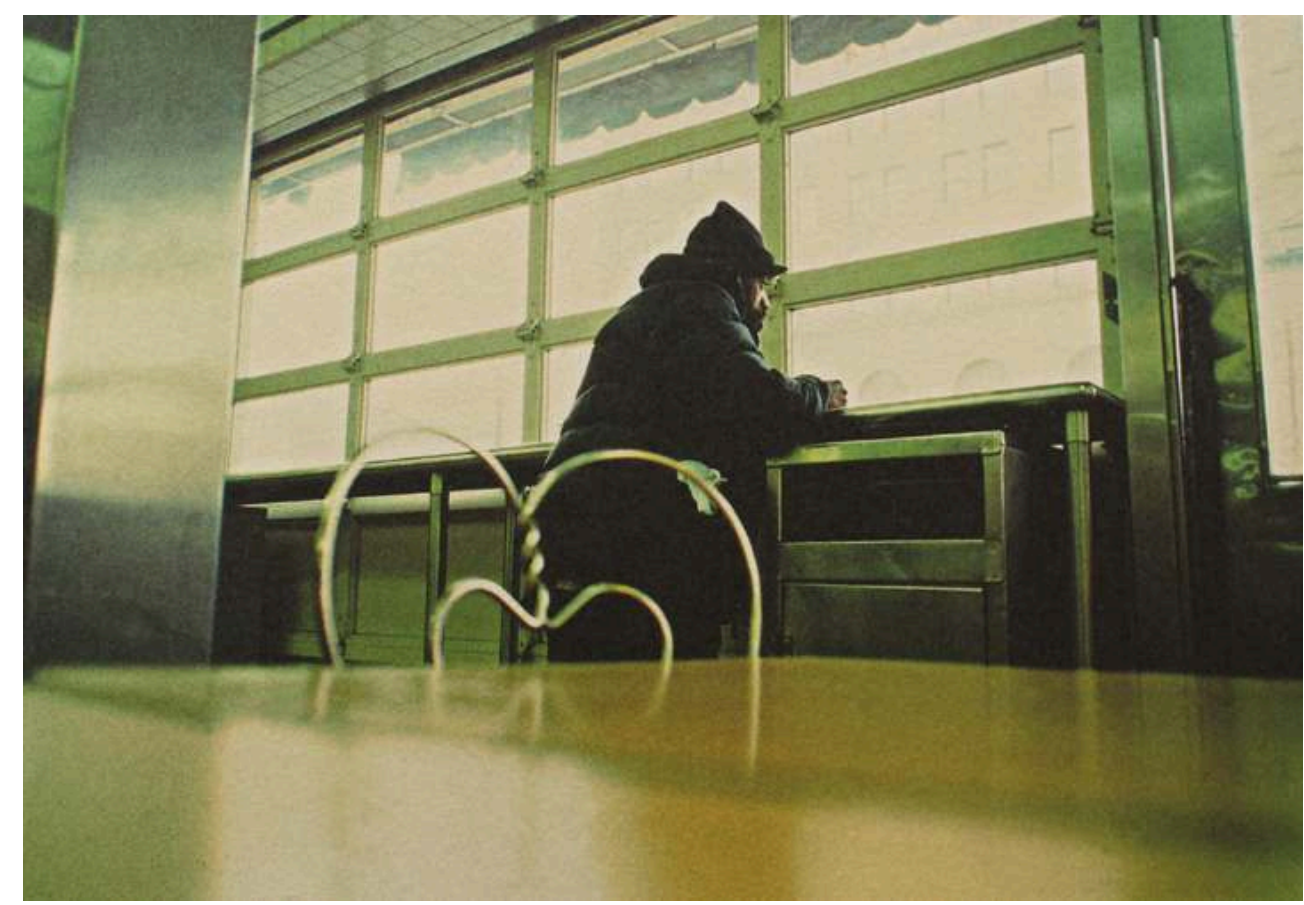

«New York, Sans titre [n.d] », p. 49

Dans son ouvrage Eclipse, Dolores Marat inclut la citation de Peter Handke: «La sensation de seuil est quelque chose de calme qui mène au-delà, sans intention. ${ }^{9} \mathrm{Il}$ s'agit de rester au seuil, avec le souci de ne pas déranger, avec seule une calme bienveillance qui, bien qu'elle reste en-deçà, sait qu'elle "mène au-delà » dans sa conscience que rien ne sert de s'approcher.

50

(enisit avec l'apparei à jamais inaccessible, s'il résiste à toute compréhension ou empathie, c'est aussi cela, la déréliction humaine, l'égarement et la solitude essentiels. Là où la photo aurait aimé être une main tendue, c'est une rencontre qui ne peut se faire; les scènes sont abandonnées à leur grisaille. Paradoxalement, la sensation de présence conférée par toute photographie rend ici très sensiblement l'aliénation et l'absence qui président à toute vie.

51 Dans ses entretiens, Dolores Marat dit que, pour elle, le cadrage doit être juste du premier coup, sans quoi elle jette la photo. Jamais ne s'autorise-t-elle à recadrer l'image lors du tirage. Pour qu'une image trouve grâce à ses yeux et qu'elle la conserve, il faut qu'elle puisse y retrouver l'émotion initiale, celle de la prise de vue. Dolores Marat ne fabrique pas de l'image pour fabriquer de l'image, et produire a posteriori et artificiellement du ressenti: ses images respectent l'émotion et la perception de l'instant de la prise de vue. Autrement dit, son rapport avec l'objet-photographie doit être le même qu'avec la scène qu'elle a repérée lors de ses déambulations. C'est pourquoi ses photographies dégagent une sincérité et une humanité rares.

\section{Traces d'un art naïf de rue ; des jouets et les poubelles}

Dolores Marat est attentive à la poésie qui surgit dans les lieux délaissés, sans visibilité particulière. Elle capte les dessins tracés au hasard dans les rues, que ce soit un dessin d'enfant sur du macadam, des images d'apprentis artistes devant un terrain vague 
jonché de déchets (34-5), des peintures murales sur des façades aveugles aux vitres cassées $(52,72,145)$, ou encore une femme en bas-relief sur du sable (72).

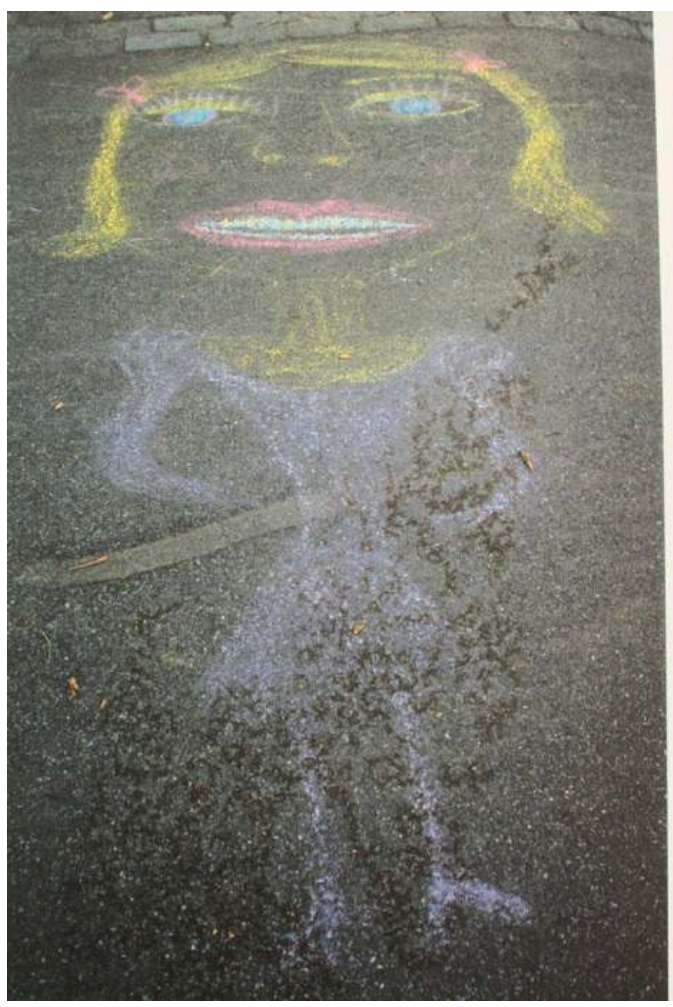

«Sans titre $[$ n.d] », p. 24

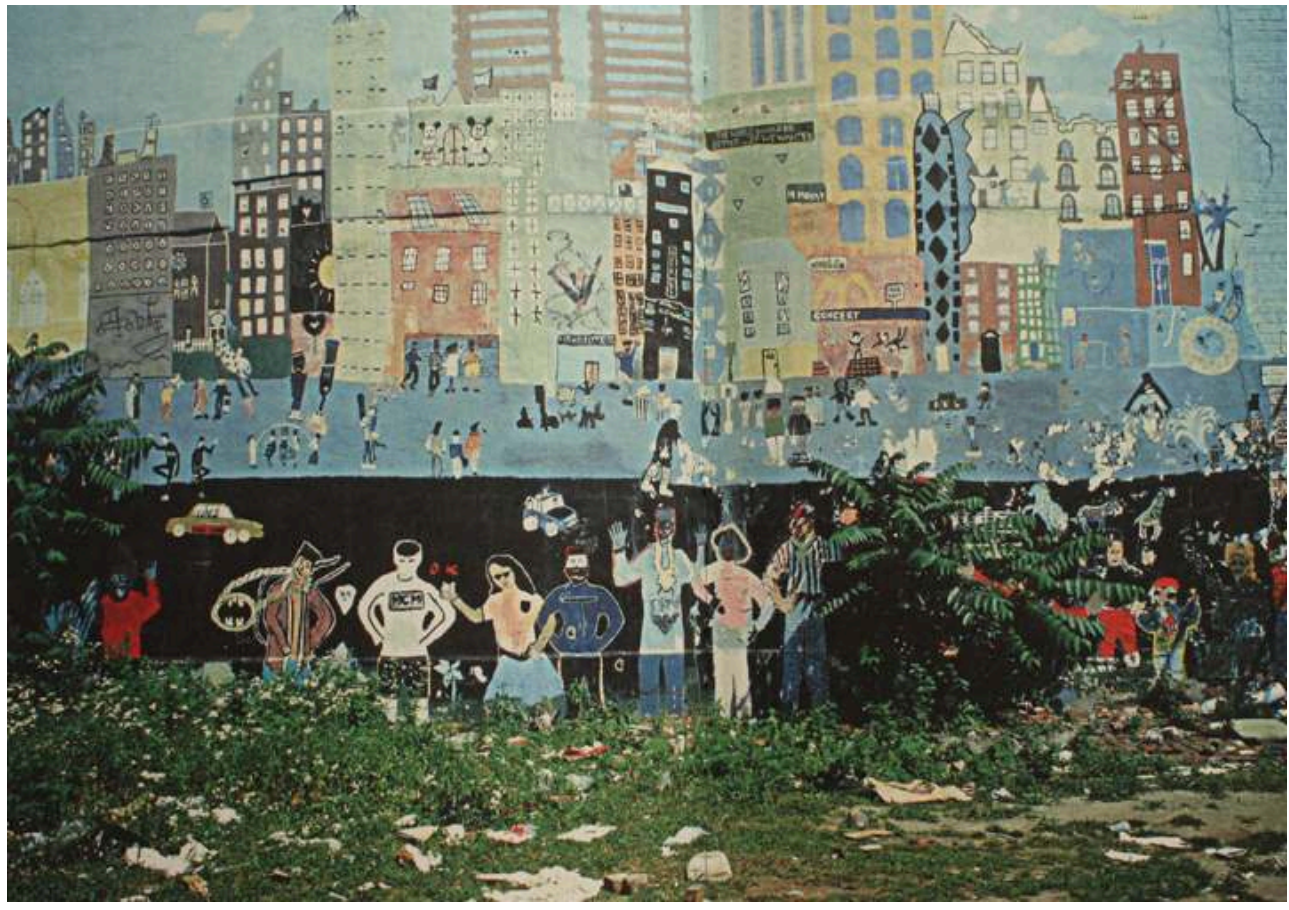

« New York, Sans titre [n.d] », p. 34-5

53 Dans un terrain vague, devant des barres d'immeubles bruns, un manège avec une armature métallique semble une gigantesque araignée à la Louise Bourgeois (50-1). Devant, l'indéfectible barrière. 


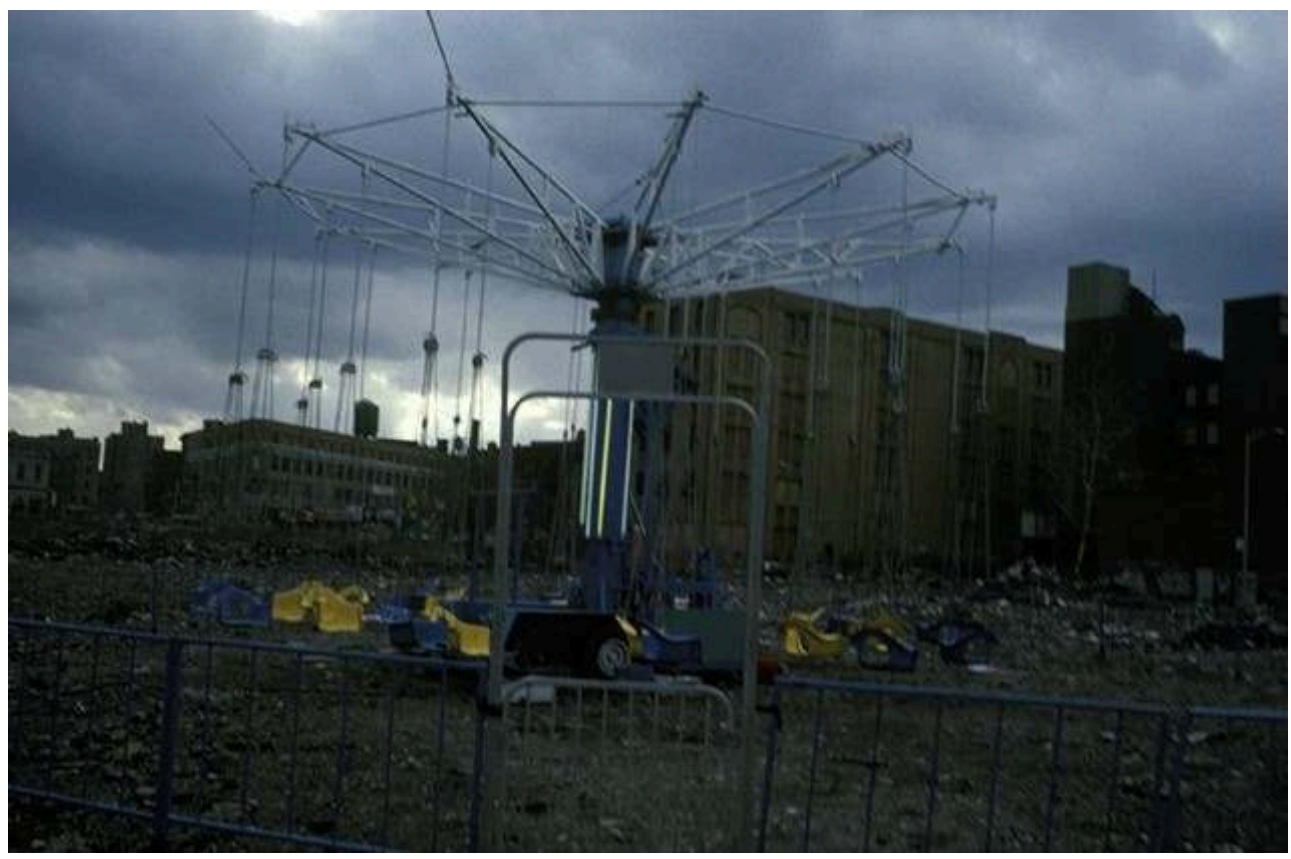

« New York, Sans titre [n.d] », p. 50-1

Dolores Marat déniche le petit merveilleux dans les endroits les plus insignifiants, les moins doués d'intérêt, comme une scène d'Alice au pays des merveilles en mosaïque d'ombres sur les murs du métro (150-1). Sans chercher vraiment à réhabiliter l'art naïf et la fantaisie à deux sous, elle les porte à l'attention du spectateur.

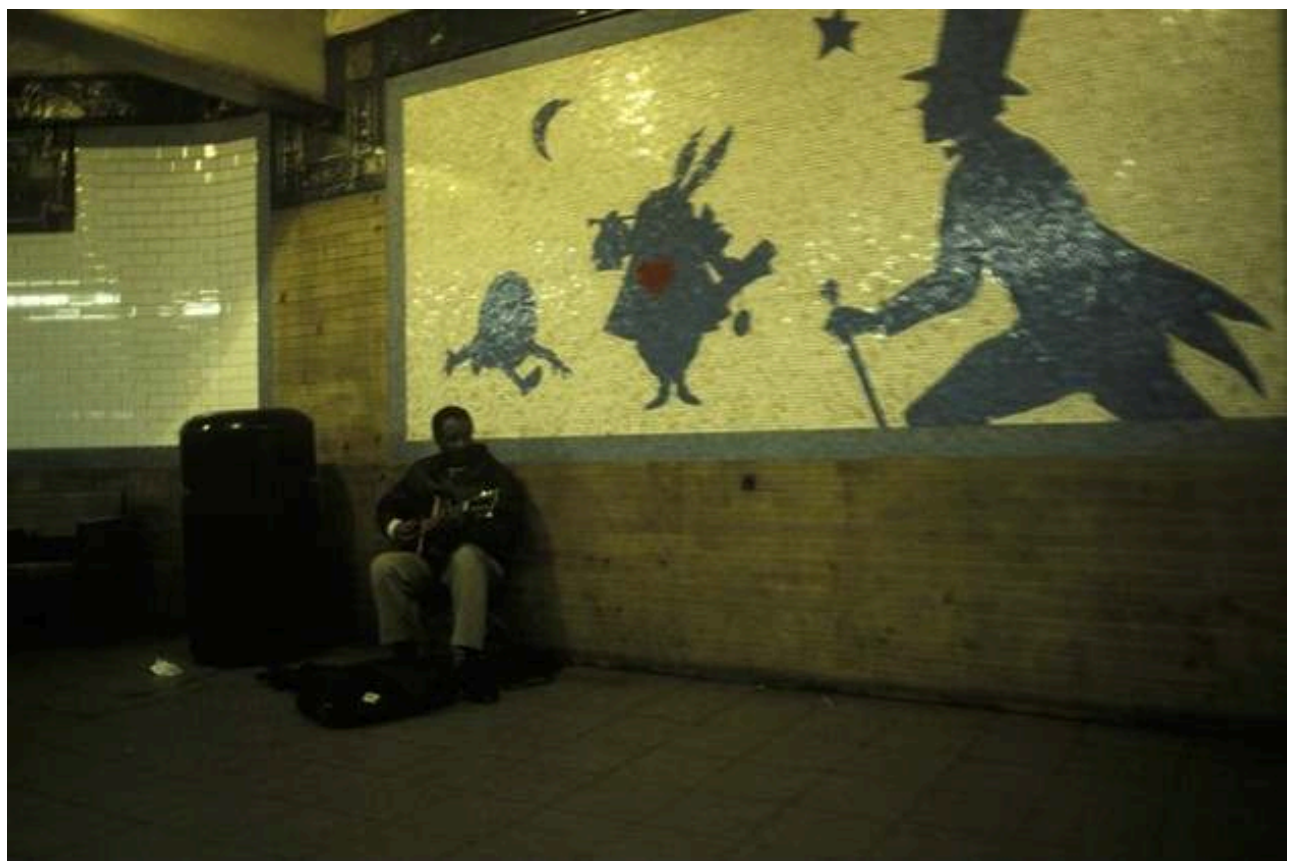

« New York, Sans titre [n.d] », p. 150-1

Dolores Marat met en relation les poubelles et les jouets. Les mannequins ou poupées sont souvent sous plastique et il n'est pas toujours clair si les jouets dans des sacs plastiques sont en attente d'être ouverts ou s'ils sont dans des poubelles. 


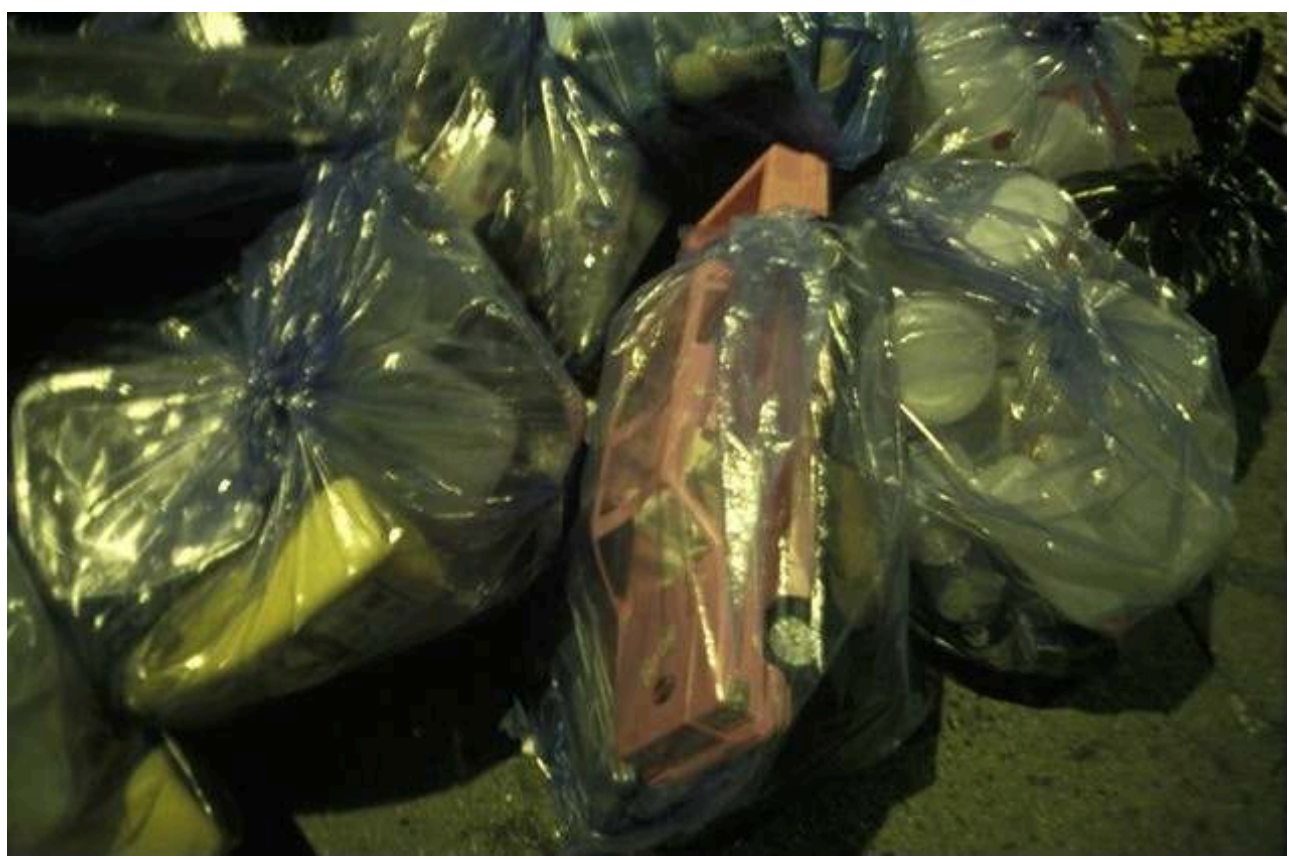

« New York, Sans titre [n.d] », p. 127

De photo en photo, par contamination et proximité graphique, les poubelles deviennent des sortes de jouets qu'elle transforme en scintillements par les éclats de lumière (127) ou auxquels elle confère le beau rôle en les affichant au premier plan (57). Les déchets font miroiter un univers ludique. Cette ambiguïté, où la fantaisie se mêle au rebut, émaille toute sa production. Les mannequins ou jouets sous plastique rappellent ce trompettiste, dont on perçoit les contours indistincts dans sa voiture (180): son pouvoir expressif est ainsi dénié, étouffé.

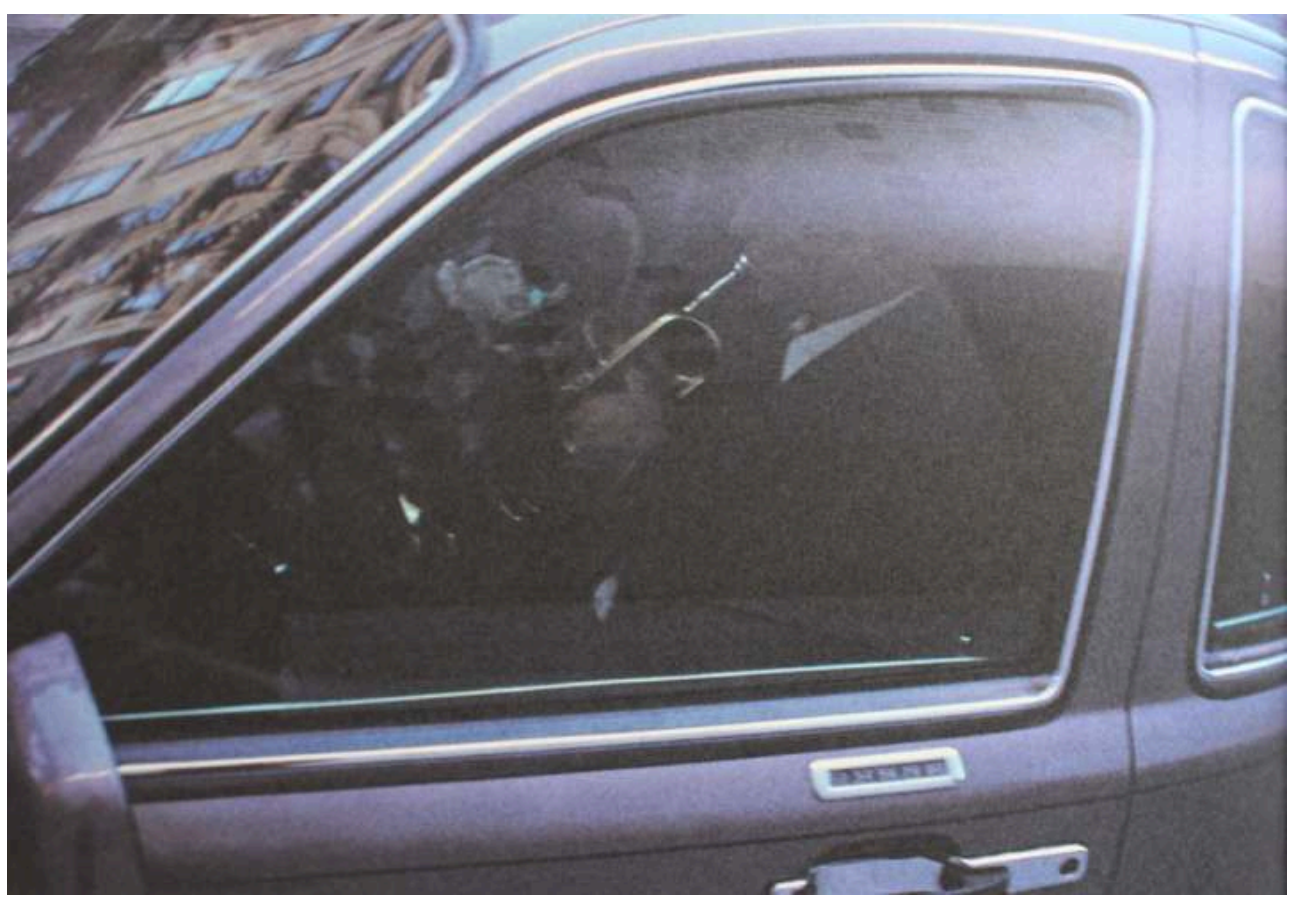

« New York, Sans titre [n.d] », p. 180 
57 Les poubelles qui incarnent le déconsidéré sont porteuses d'un symbolisme autobiographique, ainsi que de connotations métapicturales évidentes.

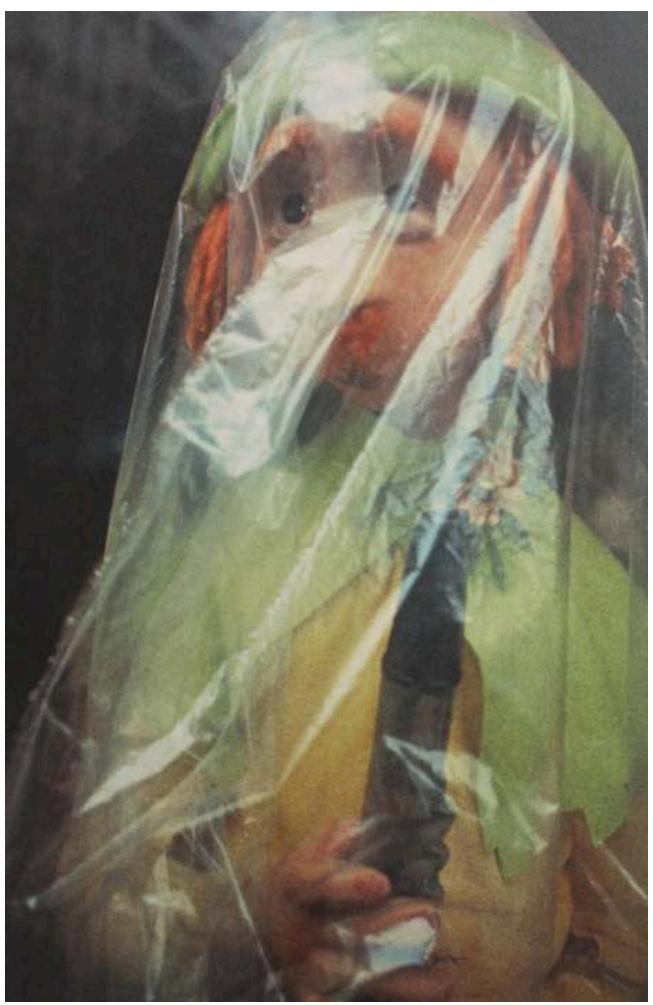

« New York, Sans titre [n.d] », p. 196

58 Une des photos montre un corps tatoué (104). L'on se souvient que Dolores fut, enfant, pathologiquement marquée sur son corps après des découvertes traumatisantes concernant son origine et son identité. La marque, l'enfance et le rejet sont comme indissolublement liés dans son esprit. Ici et là, surgissent dans ses photographies quelques éclairs de réminiscences de sa vie personnelle. Ainsi, des représentants de l'ordre sont associés de manière un peu saugrenue à la sphère domestique ou au monde forain. La silhouette sérieuse d'un shérif se reflète dans une vitrine ou une fenêtre de maison décorée avec des objets artisanaux de Noël sans prétention. Un policier est adossé à un tuyau devant une bouche de métro telle une «bulle » ou gueule noire (101) qui rappelle celle des lions de la page de couverture. 


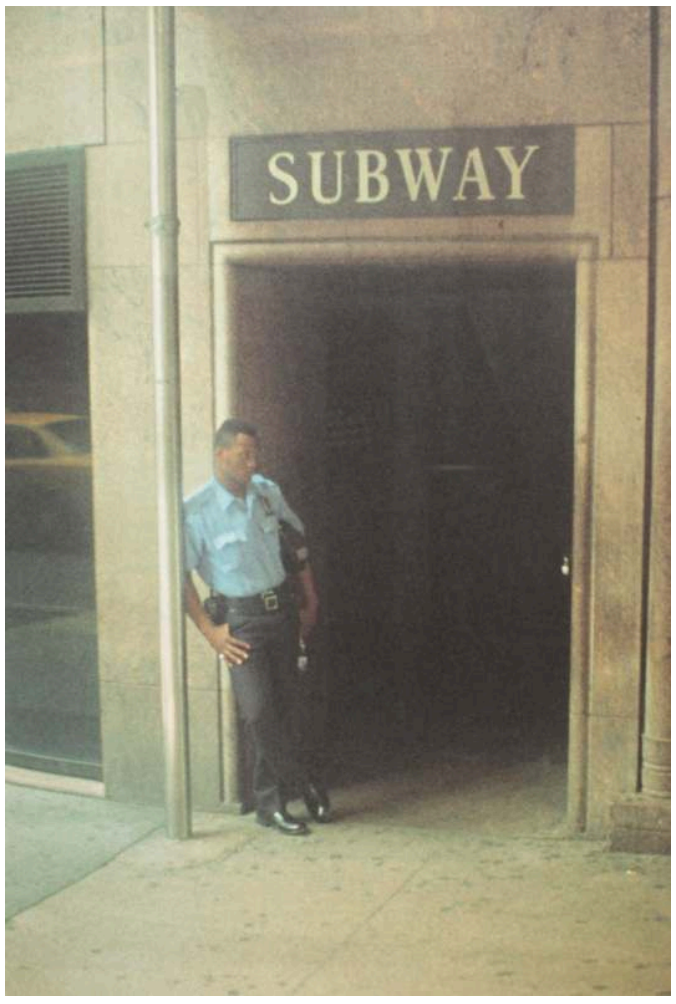

« New York, Sans titre [n.d] », p. 101

Des suggestions de violence sourdent de temps en temps. King Kong apparaît deux fois, dont une fois avec des couleurs sanguinolentes (88).

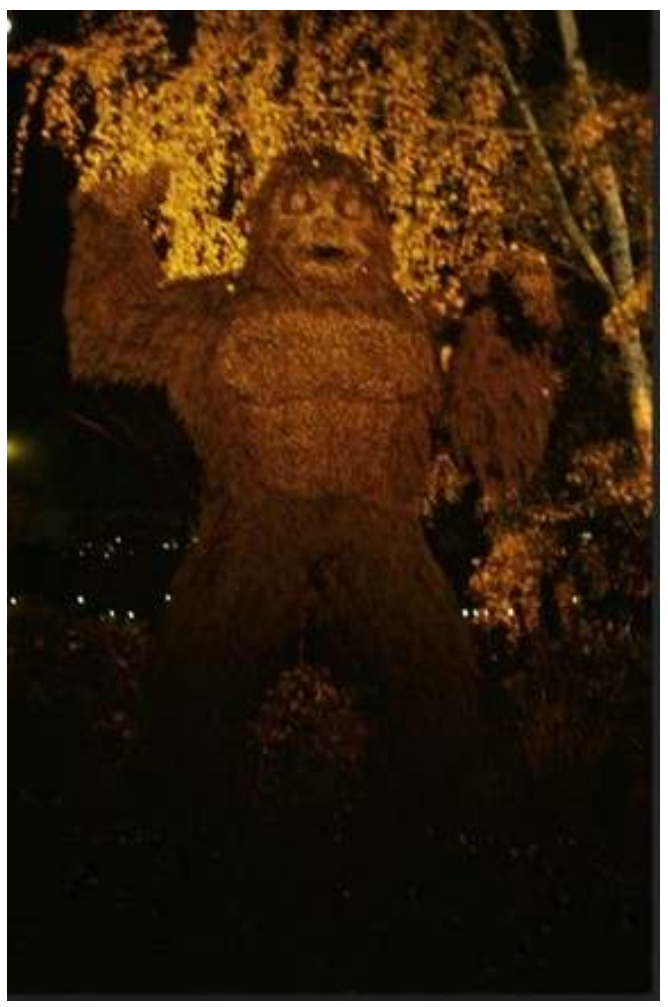

«New York, Sans titre [n.d] », p. 88 
Un poisson coupé en deux (136) ou de monstrueux morceaux de viandes sur crochets (169) rendent un peu perturbant l'insolite d'un requin en plastique accroché aux arbres (153) ou de deux personnes jouant avec des fausses mitraillettes (160).

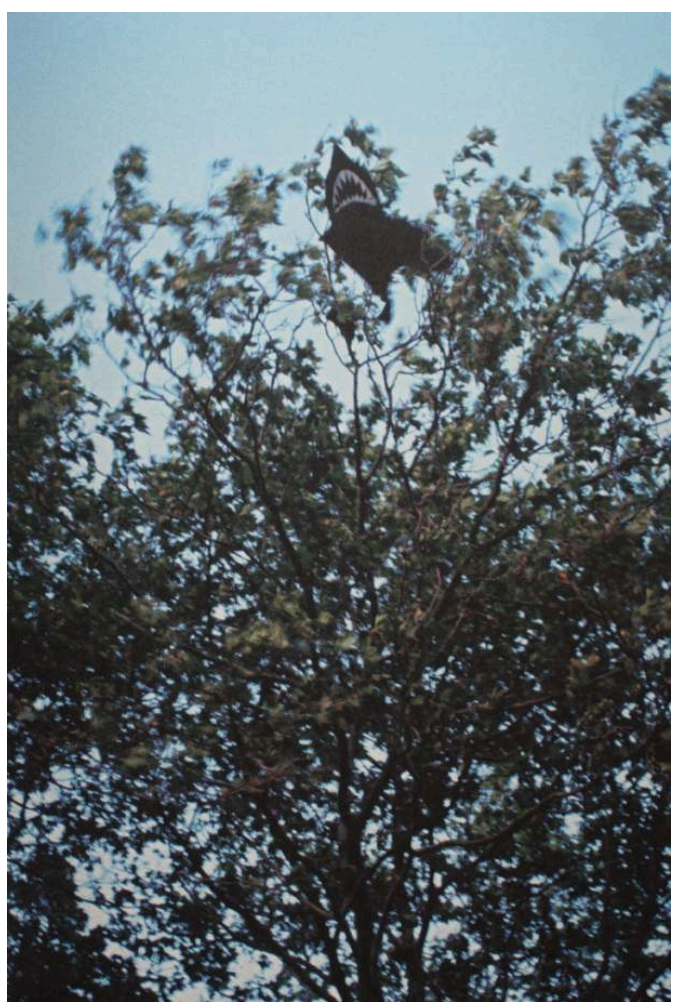

« New York, Sans titre [n.d] », p. 153

Et face à ces suggestions discrètes mais pesantes, un texte dans son ouvrage Labyrinthe semble prémonitoire. Il s'agit d'un bout de The Narrative of Arthur Gordon Pym of Nantucket d'Edgar Allen Poe, traduit par Baudelaire. Cet extrait est celui où le protagoniste éprouve " un immense désir de tomber ", " une tendresse pour l'abîme ». "Les bras des fantômes ", le "vacillement " peuvent qualifier de manière figurée l'indistinction et l'immatérialité des photographies ${ }^{10}$, mais le vertige ressenti est, pour les personnages enfermés dans leur monde, celui d'une chute annoncée, littérale et symbolique, une chute dans le monde réel, pour en éprouver toute la concrétude et la dureté. En témoigne cette photographie, ici prise à Bastia en Corse, prémonitoire d'événements autobiographiques. 


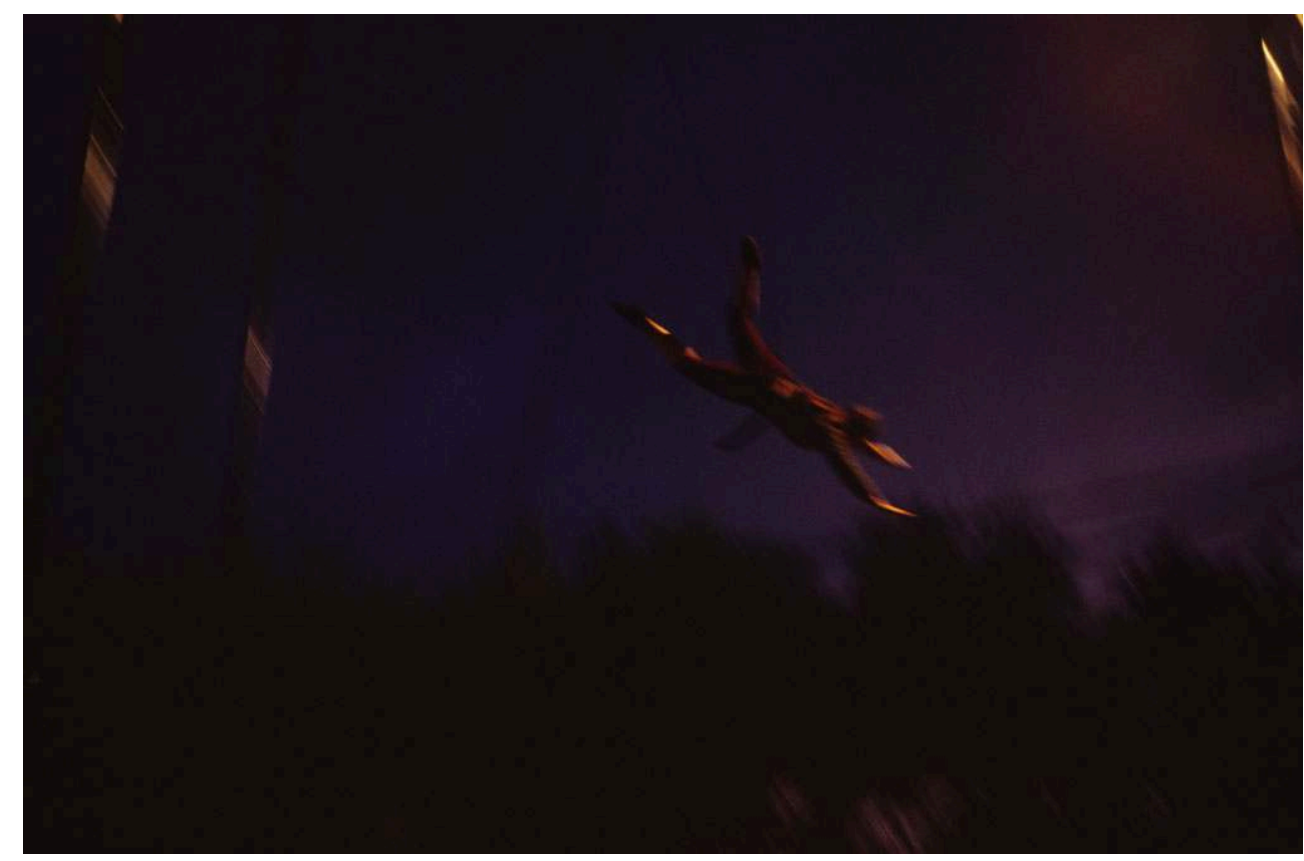

«Bastia, Sans titre [n.d] »

\section{Conclusion}

Les photographies de New York sont d'un esprit très semblable aux photographies que l'on trouve dans les autres ouvrages de Dolores Marat, avec des caractéristiques et des thématiques communes : glanées au fil de ses pérégrinations et errances, des personnes prostrées dans leur solitude, perdues dans leurs pensées derrière ou devant des vitres opaques, des personnes en retrait, un peu désemparées, réfugiées dans leur introversion; des lieux désaffectés, que la photographe représente en gardant les distances qui s'imposent; l'utilisation du gris crépusculaire, pour ne pas mentir sur le caractère blafard et effacé de ces lieux sordides ; la profondeur bouchée des couloirs, tunnels ou escaliers; des voitures, des bars, la rue; des jouets d'enfants délaissés ; jouxtant les visages enfermés, de nombreuses têtes de mannequins enveloppés dans des sacs plastiques, à la fois protégés et étouffés (196); le monde forain et ses couleurs nocturnes; des fresques de rue ou autres modestes décors extérieurs ... En cela, le qualificatif «maratéen » que la photographe appliquait à ses images new-yorkaises est particulièrement justifié. Celles-ci ne sont accompagnées d'aucune légende, d'aucune date, et nous sont livrées hors de tout contexte prédéterminé. Nul militantisme, nulle revendication dans ces images intimistes. De résonances de son passé en prémonitions, Dolores Marat nous promène dans New York, mais aussi et surtout dans les limbes de ses songes. 


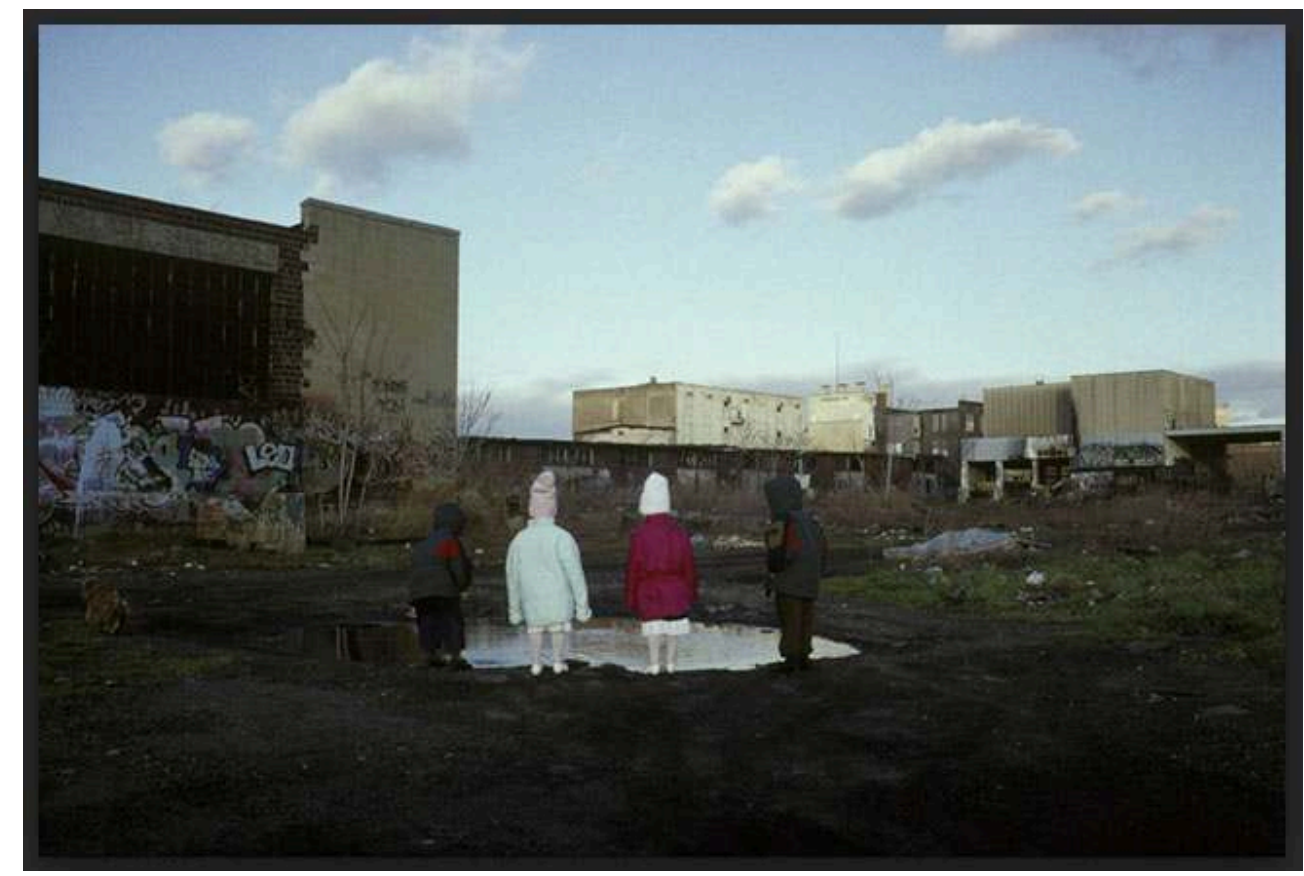

« New York, Sans titre [n.d] », p. 105

Dans une des images, quatre enfants sont debout devant une flaque réfléchissante (105). Ils sont de dos, dans un terrain vague. Au milieu de cet endroit jonché de gravats, le ciel se reflète dans la flaque lisse, que regardent les enfants rassemblés dans ce moment de grâce. Les couleurs bleue et rouge des petites filles sont reprises de part et d'autre dans les anoraks des deux petits garçons. Comme les enfants sont de dos, nous sommes invités à les rejoindre. Mentalement seulement, pas davantage. Les accents mythologiques de la scène - Narcisse, le rassemblement autour d'un puits ${ }^{11}$ - nous $y$ interdisent. La photographe a appuyé sur le bouton de son appareil, et puis a passé son chemin. Surtout ne pas faire intrusion dans le tendre de l'enfance, et son solipsisme. À distance respectueuse, furtivement, Dolores Marat capte, charmée, cette scène globalement grise, réunie autour d'une bulle crevée.

\section{BIBLIOGRAPHIE}

\section{Livre en question}

Marat, Dolores, New-York USA. Paris : Edition Marval, 2002. Préface par Patrick Roegiers.

Site de Dolores Marat :

http://www.doloresmarat.fr/photographe/dolores-marat.php

Ouvrages de Dolores Marat

MARAT, Dolores, Eclipse, Paris, Editions Contrejour, 1990.

---, Passage, Paris, In Visu, 1992. 
---, Rives, Paris, Editions Marval, 1995.

---, Histoire sans parole, Paris, Bavery, 2000.

---, Labyrinthe, Paris, Editions Le point du jour et Stockport, Dewi Lewis Publishing, 2001.

---, New-York USA, Paris, Edition Marval, 2002.

---, Illusion, cosigné avec Marie Darrieussecq, Paris, Filigranes Editions, 2003.

---, Insolite, Montreuil, Editions Chez Higgins, coll. Témoignages, 2007,

Articles de presse

BAURET, Gabriel, « Le New York de Dolores », L'Art d'aujourd'hui, du 15 au 21 novembre 2002.

BRIARD, Frédérique, « New York, côté cœur », Marianne, du 16 au 22 décembre 2002.

CHAPULS, Frédérique, « La magie du presque rien », Télérama, 13 juin 2001.

FANCHETTE, Frédérique, « A New York, Marat bout », Libération, jeudi 17 octobre 2002.

GUERRIN, Michel, « Dolores Marat - Galerie Pons », Le Monde, 1995.

GUIBOURGE, Stéphane, « New York Odyssée », Ulysse, décembre 2002/janvier 2003.

KENNEDY, Douglas, « Lost in America », The Times, Saturday April 23, 2005.

---, « Elegy and ecstasy », The Times, Saturday February 5, 2005.

LANFRANCHINI, Fabrice, GOETZ, Adrien, TARBOURIECH, Nicole, « New York USA », Zurban, mercredi 18 décembre 2002.

LE GOFF, Hervé, « Dolores Marat - L'illusion d'une fiction », Le Photographe, avril 2003.

WYNANTS, Jean-Marie, « Un étrange goût d'absence », Le Monde, 1995.

---, « New York frappée par la grâce », Le Monde, 2002.

---, « 'La photo, c'est d'abord une émotion' - Entretien », Le Monde, 2002.

Sans mention d'auteur

« New York couleur nuit de Dolores Marat », Photographie Nouvelle, 2002.

« New York, ville mythique », Ouest France, lundi 25 décembre 2002.

« New York USA », Télérama, mercredi 27 novembre 2002.

« Dolores Marat - New York USA », Les Inrockuptibles, mercredi 4 décembre 2002.

« Dolores Marat, la pointilliste », La Croix, samedi 7 décembre 2002.

« New York USA », L'Express, jeudi 12 décembre 2002.

« New York USA », Rolling Stone, décembre 2002.

«"Un livre est une fenêtre par laquelle on s'évade" », Métro, 18 décembre 2002.

« New York USA », Lire, décembre/janvier 2003.

Filmographie

Fine Arts TV, « Dolores Marat - A Place in Time », jeudi 26 mai 2011,

http://www.finearttv.tv/fr/fine-art/decouverte/dolores-marat-a-place-in-time,

(consulté en août 2013). 
GONNET, Jean-Louis (réalisateur), « New York Couleur nuit », Coup d'œil, Derrière la page, de Christian Caujolle et Caroline Parent,

http://www.doloresmarat.fr/photographe/dolores-marat.php,

(consulté en août 2013).

\section{Sitographie}

In Camera, http://www.incamera.fr/Portfolio.html (consulté en août 2013).

Néon et Galerie Françoise Besson, « Dolores Marat », http://www.chezneon.fr/site_old/artistes/PDF/49.pdf (consulté en août 2013).

Le Blog de la Photographie « Photo sensible », par Jean- Sébastien Stehli « Dolores Marat chez in camera»

http://blog.madame.lefigaro.fr/stehli/2011/04/dolores-marat.html (consulté en août 2013).

Tallis Photography,

http://tallisphotography.weebly.com/dolores-marat.html

(consulté en août 2013).

CreativTv.net

http://www.creativtv.net/v2/photo2002/marat.html

(consulté en août 2013).

Paris Art, 2007 et 2010.

http://www.paris-art.com/evenement-culturel/carte-blanche-a-dolores-marat/dolores-marat/ 2019.html

http://www.paris-art.com/exposition-art-contemporain/sirocco/marat-dolores/11275.html (consulté en août 2013).

La critique. org, « Mise au point floue sur la ville, le loup et les belles - Expositions Dolores Marat / Lucja Ramotowski-Brunet » http://www.lacritique.org/article-mise-au-point-floue-sur-la-ville-le-loup-et-les-belles (consulté en août 2013).

Photoclub Montreuil

http://photoclub-montreuil-slv11.blogspot.fr/2013/06/dolores-marat.html

(consulté en août 2013).

\section{NOTES}

1. Voir entretien avec Dolores Marat, le 24 août 2014 en Avignon, par Muriel Adrien. In Transatlantica, 2014.

2. Toutes les photographies dont il est fait référence ici sont issues de l'ouvrage New York (Paris, Editions Marval, 2002) de Dolores Marat, et les nombres entre parenthèses sont les pages de photographies qui peuvent faire figure d'exemples des idées évoquées au fil du texte.

3. La référence à Hopper est valable aussi dans les photographies d'autres ouvrages de Dolores Marat, qu'il s'agisse de l'ambiance dégagée par les photographies ou même plus littéralement des scènes, comme celles avec des bars ou des stations essence (cf Marat, Labyrinthe, 14). Par contre, le rapprochement serait fortuit, car Dolores Marat dit ne pas avoir connu les œuvres de Hopper 
avant de commencer son travail personnel. Ce n'est qu'en 2000 qu'elle a regardé de près la peinture de Hopper.

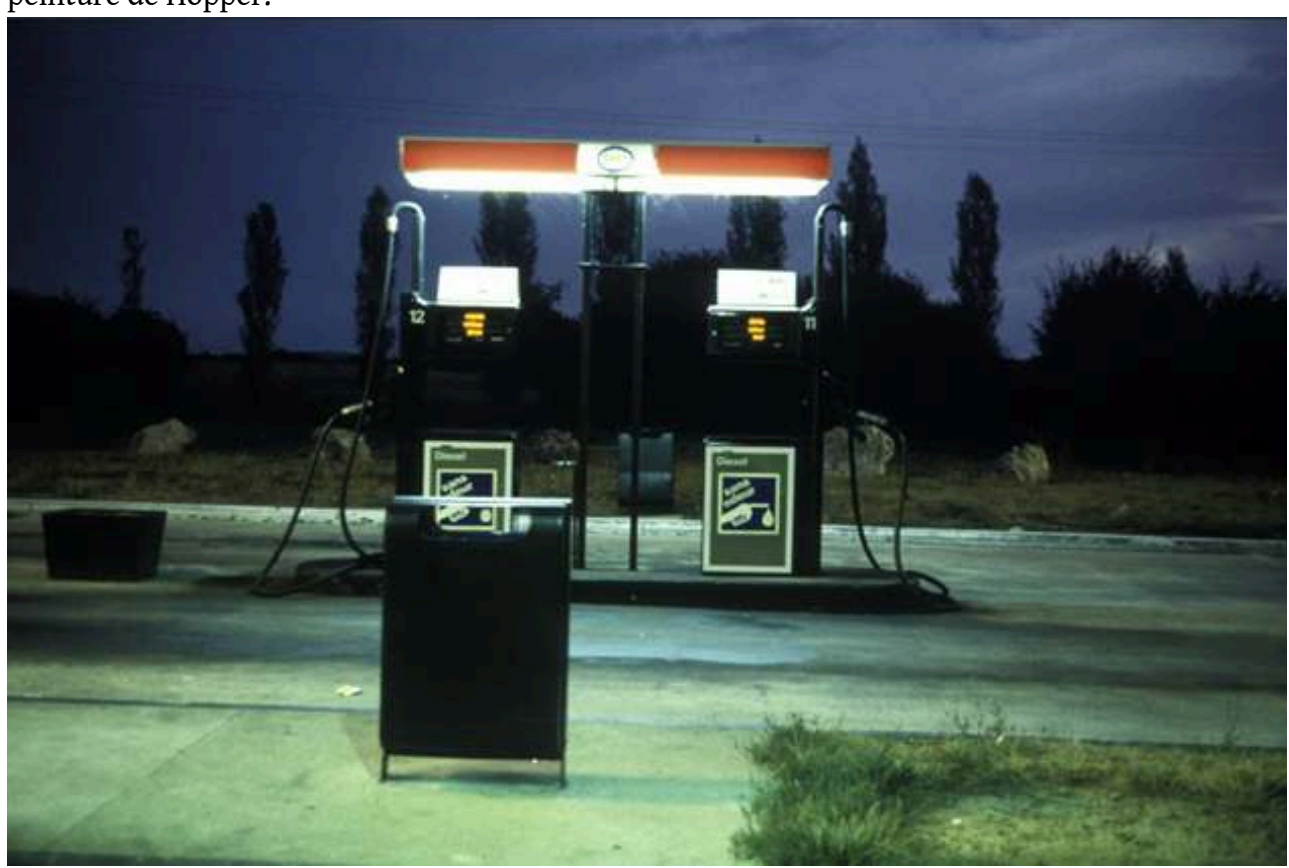

«Sans titre [n.d], Labyrinthe, p. 14 »

4. Voir entretien avec Dolores Marat, le 24 août 2014 en Avignon, par Muriel Adrien. In Transatlantica, 2014.

5. Marat, Dolores, Passage, Paris, In Visu, 1992.

6. Ce projet fut évoqué lors de l'entretien du 24 août 2014 en Avignon. Muriel Adrien. In Transatlantica, 2014.

7. En effet, la première fois que Dolores Marat vint à New York, c'était pour une commande de magazine qui lui demandait de photographier des vitrines.

8. Sur son site, figure une série sur les animaux.

9. Exergue de MARAT, Dolores, Eclipse, Paris, Editions Contrejour, 1990.

10. Cf aussi le titre de l'ouvrage de Marie Darrieussecq, amie de Dolores Marat, avec qui elle a collaboré, La Naissance des fantômes.

11. Voir La Tête maléfique (The Baleful Head) de Burne-Jones par exemple.

\section{INDEX}

Mots-clés : New York, photographie contemporaine, Edward Hopper, tirages Fresson

Keywords : New York, contemporary photography, Edward Hopper, Fresson prints 